\title{
Lung development and immune status under chronic LPS exposure in rat pups with and without CD26/DPP4 deficiency
}

\author{
Andreas SchmiedI ${ }^{1,4}$ (I) Inga Wagener ${ }^{1} \cdot$ Meike Jungen $^{1} \cdot$ Stephan von Hörsten ${ }^{2} \cdot$ Michael Stephan $^{3}$
}

Received: 5 October 2020 / Accepted: 5 September 2021 / Published online: 4 October 2021

(c) The Author(s) 2021

\begin{abstract}
Dipeptidyl-peptidase IV (CD26), a multifactorial integral type II protein, is expressed in the lungs during development and is involved in inflammation processes. We tested whether daily LPS administration influences the CD26-dependent retardation in morphological lung development and induces alterations in the immune status. Newborn Fischer rats with and without CD26 deficiency were nebulized with $1 \mu \mathrm{g}$ LPS $/ 2 \mathrm{ml} \mathrm{NaCl}$ for $10 \mathrm{~min}$ from days postpartum (dpp) 3 to 9 . We used stereological methods and fluorescence activated cell sorting (FACS) to determine morphological lung maturation and alterations in the pulmonary leukocyte content on dpp 7, 10, and 14. Daily LPS application did not change the lung volume but resulted in a significant retardation of alveolarization in both substrains proved by significantly lower values of septal surface and volume as well as higher mean free distances in airspaces. Looking at the immune status after LPS exposure compared to controls, a significantly higher percentage of B lymphocytes and decrease of $\mathrm{CD} 4{ }^{+} \mathrm{CD} 25^{+} \mathrm{T}$ cells were found in both subtypes, on dpp7 a significantly higher percentage of $\mathrm{CD} 4 \mathrm{~T}^{+}$cells in CD26 $6^{+}$pups, and a significantly higher percentage of monocytes in $\mathrm{CD}_{26^{-}}$pups. The percentage of T cells was significantly higher in the CD26-deficient group on each dpp. Thus, daily postnatal exposition to low doses of LPS for 1 week resulted in a delay in formation of secondary septa, which remained up to dpp 14 in $\mathrm{CD}_{2} 6^{-}$pups. The retardation was accompanied by moderate parenchymal inflammation and CD26-dependent changes in the pulmonary immune cell composition.
\end{abstract}

Keywords Rat · Lung development $\cdot$ Lipopolysaccharide (LPS) $\cdot$ CD26/DPP4 $\cdot$ Immune cells

\section{Introduction}

CD26/DPP4, called CD26 in the following, is mainly expressed in kidneys and lungs and is involved in different inflammation processes (Mentlein 1999; Klemann et al.

Stephan von Hörsten and Michael Stephan contributed equally.

Andreas Schmiedl

Schmiedl.Andreas@mh-hannover.de

1 Functional and Applied Anatomy, Hannover Medical School, Carl-Neuberg Str. 1, 30625 Hannover, Germany

2 Department of Experimental Therapy University Hospital Erlangen and Preclinical Experimental Center (PETZ), Friedrich-Alexander-University Erlangen-Nürnberg, Bavaria, Germany

3 Clinic for Psychosomatics and Psychotherapy, Hannover Medical School, 30625 Hannover, Germany

4 Biomedical Research in Endstage and Obstructive Lung Disease Hannover (BREATH), German Center for Lung Research (DZL), 30625 Hannover, Germany
2016). Adult asthma-induced CD26/DPP4-deficient rats exhibited an attenuated inflammation combined with a reduced influx of regulatory $\mathrm{T}$ cells and a reduced upregulation of surfactant proteins (Schmiedl et al. 2010). Also, a reduced inflammation with differential expression of surfactant proteins in CD26/DPP4 deficient rats was seen after lipopolysaccharide (LPS) administration (Zientara et al. 2019). LPS is the biologically active component and primary recognition element in the wall of gram-negative bacteria (Rossol et al. 2011). Therefore, LPS was frequently used to induce lung inflammation in adult animals (Kawasaki et al. 2018; Liu et al. 2013), newborns (Franco et al. 2002), or fetuses (Cao et al. 2009; Kramer et al. 2009; Ueda et al. 2006). The activated signal cascade leads then to an expression of immunoregulatory genes associated with synthesis and release of pro- and anti-inflammatory cytokines like IL-1, Il-6, Il-8, and Il-10 and tumor necrosis factor $\alpha$ (Martin and Frevert 2005; Takeda et al. 2003).

Stages of lung development in mammals are similar (Zoetis and Hurtt 2003). However, rodents are born with 
morphologically immature lungs comparable to human premature infant (Burri 2006). Alveolarization starts on postnatal day (day(s) postpartum, dpp) 4 in rats. So, the developmental lung stages dpp 3-5 are comparable with those of infants, which are born earlier than the 30th week postmenstrual fetal stage. Furthermore, this time period is a critical window, because exposure to injurious noxa can disrupt lung alveolarization and vascularization (Nardiello et al. 2017). After bulk alveolarization combined with vascular maturation lasted up to dpp 21, continued alveolarization occurred until adulthood (Schittny 2017). We have already shown that CD26 deficiency delayed the postnatal lung development (Hupa et al. 2014; Wagener et al. 2020) and that high doses of postnatal LPS inhalation $(100 \mu \mathrm{g} / 2 \mathrm{~mL}$ $\mathrm{NaCl}$ ) given for $10 \mathrm{~min} 1$ day before and 1 day after the onset of alveolarization produced an acute but weakly pronounced inflammation and a delay in morphological lung development with a reduced morphological recovery after the end of LPS exposure in dependence of CD26 deficiency (Wagener et al. 2020). While this procedure resembles an acute injury, the repetitive administration of LPS over 1 week used in the present is more comparable with a chronic inflammatory disorder (Wang et al. 2009), which is a possible precondition to develop bronchopulmonary dysplasia (BPD) (Baker and Alvira 2014). BPD is a chronic disorder of the developing lung that occurs in preterm infants secondarily to an imbalance between lung injury and repair (Jobe 2015), often leading to an impairment of alveolarization (Coalson 2006). Several authors propose that postnatal infection /inflammation is a more important precursor for the development of BPD than antenatal infection (Jensen and Schmidt 2014; Ballard et al. 2016). Furthermore, inflammation caused by LPS is necessary to eliminate the pathogen. Therefore, an adequate immune response is a precondition (Hotchkiss et al. 2013). However, chronic exposure to low-dosed endotoxins such as LPS in early life may protect against atopic sensitization and IG-E-mediated diseases, but may negatively affect the lung accompanying wheezing according to the so-called hygiene hypothesis (Eder and von Mutius 2004). Furthermore, chronic exposure to endotoxin may, in contrast to acute LPS exposure, lead to some tolerance of endotoxins, leading to weaker LPS impact, e.g., after intraamniotic infection as shown by others (Kramer et al. 2009; Kallapur et al. 2007; Collins et al. 2013). There is no information about the influence of LPS exposure during the alveolarization period on morphological lung maturation and on immunological behavior in dependence of CD26 expression. Up to now, studies on the influence of inflammation on immune response in dependence of CD26 deficiency were carried out on adult rats (Kruschinski et al. 2005, 2008; Reinhold et al. 2009). Therefore, in this study, we tested the hypothesis that a 10 -min LPS nebulization ( $1 \mu \mathrm{g}$ LPS $/ 2 \mathrm{ml} \mathrm{NaCl})$, carried out for 7 days from dpp 3 to dpp 9, leads to a stronger pronounced delay in morphological lung development combined with an additional weak and different immune reaction in CD26-deficient lungs.

\section{Material and methods}

\section{Animals}

We used wild-type F344/Ztm rats (WT) and CD26/DPP4deficient mutant rats (F344/Crl(Wiga)SvH-Dpp4m) without CD26/DPP4-activity and CD26/DPP4-expression (Karl et al. 2003). Rats and their litters were maintained in the Central Animal Facility of Hannover Medical School according to recommendations of the Federation of European Laboratory Animal Science Associations (FELASA) (Rehbinder et al. 1996). Animal care procedures and research had been authorized by the review board of the Landesamt für Verbraucherschutz und Lebensmittelsicherheit (06/1078, LAVES; Oldenburg, Germany) and were carried out according to international guidelines on the use of laboratory animals.

\section{Experimental schedule}

Rat pups of litters were put in a closed glass chamber and inhaled low doses of LPS ( $1 \mu \mathrm{g}$ LPS $/ 2 \mathrm{ml} \mathrm{NaCl}$ ) (Gerhold et al. 2003), which was distributed with a nebulizer (Pari LC Star (Pari, Starmberg, Germany) for 10 min on each day over a period of 7 days starting on day 3 postpartum (dpp3). Controls received no LPS.

\section{Processing of lungs}

After random selection of healthy pups (controls) and pups exposed to LPS (Escherichia coli, serotype 0127:B8, Sigma, Darmstadt, Germany), the young animals of both substrains were killed on days postpartum (dpp) 7, 10, and 14 to investigate their lungs. Deep anesthesia was achieved by intraperitoneal application of a mixture of different concentrations and volumes of Medetomidin (DomitorVR $1 \mathrm{mg} / \mathrm{mL}$, Pfizer, Karlsruhe, Germany) and Ketanest (KetaminVR 100 mg/ $\mathrm{mL}$, Dr. E. Graub AG, Bern, Switzerland) depending on the postnatal stage as already described (Wagener et al. 2020). Pups were killed by aortic exsanguination.

Lungs of the following postnatal age groups were investigated:

1. 7-day-old pups, which are in the alveolarization phase (Burri 2006)

2. 10-day-old pups, which are less sensitive to stress (stress non responsive period) (Sapolsky and Meaney 1986). 
3. 14-day-old pups, which have finished the bulk alveolarization period (Tschanz et al. 2014)

\section{Histology — Stereology}

After insertion and fastening of a cannula via the larynx into the trachea, the thorax was opened, and the heart-lungblocks were taken out. Subsequently, the heart, thymus, and lymph nodes were removed.

Both lungs of each group were instilled with a mixture of cryo-gel "Tissue-Tec" (OCT, Torrance, CA, USA)/PBS (1:3) via gravitation (hydrostatic pressure $20 \mathrm{~cm} \mathrm{H}_{2} \mathrm{O}$ ) in a special instillation device. After tying off the trachea, the lung volume was determined using the fluid displacement method (Scherle 1970). Afterward, both lungs were frozen on dry ice.

Lung volume and body weight were determined and stated additionally as lung volume to body weight ratio as a measure, which was used for lung growth, particularly in preterm infants (De Paepe et al. 2014, 2005).

Using age-appropriate section protocols, the whole frozen lung blocks were completely cut from apical to basal to obtain 10 different cutting depth planes, which were all equally spaced from one another and comparable independent of age. Therefore, the $10-\mu \mathrm{m}$ cuts per animal used for evaluation were at least $560 \mu \mathrm{m}$ apart. Ten-micrometer-thick cryosections from the different cutting depths were selected randomly for evaluation.

Sectioning of each lung block was carried out using a Cryostat (Leica CM 3050S, München, Germany). After staining with hematoxylin-eosin, scanning of test fields was carried out on a Nikon Eclipse 80i microscope (Tokyo, Japan) connected to a digital camera using the Stereo Investigator Version 6 software (Micro Bright Field, Vermont, USA) as described before (Hupa et al. 2014). According to the guidelines for standardized quantitative Assessment of Lung Structure (Hsia et al. 2010), the following parameters were determined using the point and intersection counting as described before (Hupa et al. 2014; Schmiedl et al. 2017; Wagener et al. 2020):

1. Volume densities of parenchyma $\left(V_{V}(\mathrm{par} / \mathrm{par}+\right.$ nonpar)), counting test points, which hit alveoli, septa, small vessels, ductus alveolares (par) and arteries, venes, bronchi, bronchioli (nonpar) and using the formula: $P($ par $) / P($ par $)+P($ nonpar $) \times 100$

2. Volume densities of septa $\left(V_{V}(\right.$ septa/par $\left.)\right)$, counting test points, which hit alveolar septa (septa) and septa, ductus alveolares and alveoli (par) and using the formula: $P($ septa $) / P($ par $) \times 100$

3. Volume densities of parenchymal airspaces ( $V_{V}$ (airspace) par)) counting test points, which hit airspaces of alveoli, sacculi, and ductus alveolares (parenchymal airspaces) as well as septa, ductus alveolares and alveoli (par) and using the formula: $P($ airspace $) / P($ par $) \times 100$

4. Surface densities $\left(S_{V}\right)$ of septa $\left(S_{V}(\right.$ septa/par $\left.)\right)$ counting test lines, which transect the surface of septa (intersections, $I$ ) and test lines which hit the parenchyma and using the formula: $2 \times \mathrm{IS}_{\text {septa }} / \mathrm{P}(\mathrm{par}) \times 1 / 2$ length $\times 1 / 2$ length of test line

5. The volume to surface ratio of septa $\mathrm{V}_{\mathrm{S}}$-ratio ${ }_{\text {septa }}$ (mean septal wall thickness) counting the test points, which hit septa (alveolar epithelium, connective tissue, capillaries) and test lines, which transect the surface of septa (at least alveolar epithelium) and using the formula: $P($ septa $) \times 1 / 2$ length of test line $/ 2 \times I$

6. Mean linear intercepts $(M L I)$ of airspaces as a measure for the mean free distances in airspaces by counting test points which hit the alveoli and ductus alveolares and intersections with the alveoli and ductus alveolares and using the formula: $\mathrm{Lm}=4 \times V($ airpace $) / S($ alv, sac $)$

$V_{V}$ and $S_{V}$ are related to the parenchyma as reference space, which could also be subjected to alterations. Therefore, both parameters were applied to the total lung volume (Hupa et al. 2014; Schmiedl et al. 2017). To get information about total volume and surface of septa as well as about total volume of air spaces, we used the following formula:

$V($ septa;lung $)\left(\mathrm{cm}^{3}\right)=V_{V}($ septa $/$ par $) \times V_{V}($ par $/$ par + nonpar $) \times V_{\text {lung }}$.

$V($ airspace;lung $)\left(\mathrm{cm}^{3}\right)=V_{V}$ (airspace $/$ par $) \times V_{V}$ (par/par + nonpar $) \times V_{\text {lung }}$.

$S($ septa;lung $)\left(\mathrm{cm}^{2}\right)=S_{V}($ septa $/$ par $) \times V_{V}($ par $/$ par + nonpar $) \times V_{\text {lung }}$.

\section{Detection of inflammatory cells}

Inflammatory cells such as neutrophils and macrophages express the $\beta 2$-integrin $\mathrm{CD} 11 \mathrm{~b}$ as surface marker. Therefore, $10-\mu \mathrm{m}$ sections also obtained from the different cutting depths were immunostained with the avidin biotin complex method. A monoclonal mouse anti-rat CD11b antibody (clone WT-5, PharMingen, San Diego, USA) was applied as primary antibody (1:100) and a biotin-conjugated affinity purified antibody (goat anti-rat IgG, Chemicon International Europe, Hampshire, UK; 1:500) as secondary antibody. Incubation in DAB (diaminobenzidine, Perhydrol, $30 \%$, Merck, Darmstadt, Germany) substrate solution as chromogen led to a brown color of the detected inflammatory cells. The processing steps comprised blocking of endogenous peroxidase using $3 \% \mathrm{H}_{2} \mathrm{O}_{2}$ /phosphate-buffered saline (PBS) solution and incubation in avidin-D solution 
(Biotin/Avidin blocking kit SP-2001, Vector Laboratories, Burlinghame, USA). After rinsing in PBS-Tween solution and incubation in biotin solution (Biotin/Avidin blocking kit SP-2001, Vector Laboratories), sections were incubated with the primary antibody (1:00) overnight. Incubation with the secondary antibody (1:500) followed after additional rinsing for $30 \mathrm{~min}$, followed by rinsing and incubation in peroxidase conjugated streptavidin solution (Jackson ImmunoResearch Europe Ltd., Newmarket, UK) for $15 \mathrm{~min}$. After rinsing, the sections were incubated with DAB solution for $10 \mathrm{~min}$ and were rinsed several times (Wagener et al. 2020).

Immunostained inflammatory cells were counted in two sections per lung in 200-300 test fields (size of the test frame: $100 \times 100 \mu \mathrm{m}$ ) with a constant interval of $400 \mu \mathrm{m}$ between the test fields using the stereo investigator system (Micro-BrightField). Data were expressed as cell profile number per square millimeter (Wagener et al. 2020). However, this parameter was evaluated in a single section and has therefore some limitations. No statement is possible about the cell number, because the appearance of cell profiles in a single section was influenced by cellular alterations such as hypertrophy or shrinkage or swelling. However, this parameter read as cell profile density was only used to obtain some information about LPS-dependent influx of inflammatory cells.

The inflammatory status was determined on lung sections of 7- and 10-day-old pups ( $n=3$, each).

\section{FACS}

The whole lung was homogenized using $50 \mathrm{ml}$ phosphatebuffered saline (PBS; Seromed, Berlin, Germany) with 1\% bovine serum albumin (BSA, Merck, Darmstadt, Germany) and $0.1 \%$ sodium acid (Sigma) as rinsing solution. After different centrifugation and resuspension steps, incubation with $20 \mathrm{ml}$ erythrocytes lysis buffer (Schwinzer-lysis) followed. A suspension of 1 million cells per labeling was filled up with $100 \mu \mathrm{l}$ of rinsing solution $(\mathrm{PBS}+1 \% \mathrm{BSA}+0.1 \%$ sodium azide), and each transferred to a well of a microtiter plate (Greiner, Solingen Germany). FACS analyses were carried out using a FACSCanto flow cytometer (BD FACSCanto, Heidelberg, Germany), as already described (Skripuletz et al. 2007). Briefly, commercially available antibodies of different specificity (all from AbD Serotec, Duesseldorf, Germany) were used to analyze the different leucocyte and lymphocyte subpopulations, shown in Table 1. The dilutions of primary and secondary antibodies are listed in Table 2. The medium was transferred to FACS tubes filled with $300 \mu \mathrm{l}$ measuring buffer. At least 50,000 events were counted in the mononuclear cell gate, defined previously, and the results were expressed as a proportion of lung leucocytes (Kruschinski et al. 2005; Skripuletz et al. 2007).
Table 1 Primary antibodies used for FACS-Analysis

\begin{tabular}{lll}
\hline Antibody & Antigen-specificity & Subpopulation \\
\hline R73 & T cell rezeptor of rat & T lymphocytes \\
Ox12 & Immunoglobulin M of rat & B lymphocytes \\
Ox39 & IL-2 receptor (CD25) of rat & Activated T lymphocytes \\
W3/W25 & CD4 of rat & $\mathrm{CD}^{+} \mathrm{T}$ cells \\
Ox8 & CD8 of rat & $\mathrm{CD} 8^{+} \mathrm{T}$ cells \\
ED9 & CD172 of rat & monocytes /macrophages \\
\hline
\end{tabular}

The evaluation of the FACS data was carried out with the computer program Cell Quest (Becton Dickinson, San Jose, CA, USA). The ratios of the cells were displayed graphically in a dot plot graph. Depending on the cell size and granularity, the cell populations of lymphocytes, monocytes, and granulocytes were differentiated from each other, and cell cluster of mononuclear cells (lymphocytes and monocytes) was gated and selected from other cells. After selection of lymphocytes, their subpopulations were gated and differentiated based on the fluorescence intensity of the labeled cells. Single-color fluorescence was measured and evaluated in a fluorescence histogram. Two-color fluorescence was measured and evaluated in the dot plot graph. The basic fluorescence of cells when excited with light (autofluorescence) was differentiated from the antibody-mediated fluorescence and excluded. Only the antibody-mediated fluorescence was marked. Only these signals within the marked area (M1) were rated as positive and taken into account for evaluation (Pabst et al. 2003).

\section{Statistics}

The entire graphics were created with the computer program "GraphPad Prism 6.07." In the figures and tables, all data were plotted as arithmetic mean \pm standard deviation (SD), if not indicated otherwise.

The calculations were done with the statistics program “Stat View 5.0” for windows (SAS Institute Inc., Cary, North

Table 2 Primary antibodies used for FACS-analysis

\begin{tabular}{ll}
\hline Primary antibody/dilution & Secondary antibody/dilution \\
\hline Ox 39/1:100 & $\begin{array}{l}\text { Phycoerythrin conjugated } \\
\text { (kappa PE. Danova, }\end{array}$ \\
& Hamburg, Germany)/1:50 \\
Ox12 FITC conjugated/1:100 & - \\
Ox8 FITC conjugated/1:500 & - \\
R73 biotinylated/1:50 & $\begin{array}{l}\text { Per-CP peridinin- } \\
\text { chlorophyll-protein- } \\
\end{array}$ \\
& complex (R\&D Systems, \\
& USA)/1:500
\end{tabular}

W3/25 APC conjugated/1:200 
Table 3 Postnatal body weight (BW) and lung volume $(\mathrm{LV})($ mean $\pm \mathrm{SD})$

\begin{tabular}{|c|c|c|c|c|c|c|c|c|c|}
\hline \multirow[t]{2}{*}{ Genotyp } & \multicolumn{3}{|l|}{ Dpp 7} & \multicolumn{3}{|l|}{ Dpp 10} & \multicolumn{3}{|l|}{ Dpp 14} \\
\hline & BW & LV & $\mathrm{LV} / \mathrm{BW}$ & BW & LV & $\mathrm{LV} / \mathrm{BW}$ & BW & LV & LV/BW \\
\hline $\begin{array}{l}\mathrm{CD} 26^{+} \text {control }(n=3 / \\
\text { group })\end{array}$ & $11.0 \pm 2.0 \mathrm{~g}$ & $0.81 \pm 0.06 \mathrm{ml}^{*}$ & 0.074 & $14.3 \pm 4.7 \mathrm{~g}$ & $1.24 \pm 0.05 \mathrm{ml}^{*}$ & 0.087 & $20.3 \pm 1.5 \mathrm{~g}$ & $1.41 \pm 0.010 \mathrm{ml}^{*}$ & 0.070 \\
\hline $\begin{array}{l}\text { CD26 } 6^{+} \text {LPS exposed } \\
(n=3 / \text { group })\end{array}$ & $12.5 \pm 1.1 \mathrm{~g}$ & $0.78 \pm 0.03 \mathrm{ml}^{*}$ & 0.062 & $14.0 \pm 2.0 \mathrm{~g}$ & $1.23 \pm 0.05 \mathrm{ml}^{*}$ & 0.088 & $19.9 \pm 5.3 \mathrm{~g}$ & $1.42 \pm 0.06 \mathrm{ml}$ & 0.071 \\
\hline $\begin{array}{l}\mathrm{CD} 26^{-} \text {control }(n=5 / \\
\text { group })\end{array}$ & $10.1 \pm 0.5 \mathrm{~g}$ & $0.62 \pm 0.08 \mathrm{ml}$ & 0.060 & $14.3 \pm 0.9 \mathrm{~g}$ & $0.85 \pm 0.056 \mathrm{ml}$ & 0.059 & $21.0 \pm 1.6 \mathrm{~g}$ & $1.21 \pm 0.05 \mathrm{ml}^{*}$ & 0.058 \\
\hline $\begin{array}{l}\text { CD26- LPS exposed } \\
\text { ( } n=3 \text { /group) }\end{array}$ & $10.5 \pm 0.7 \mathrm{~g}$ & $0.58 \pm 0.03 \mathrm{ml}$ & 0.055 & $13.7 \pm 0.7 \mathrm{~g}$ & $0.80 \pm 0.045 \mathrm{ml}$ & 0.058 & $22.0 \pm 1.6 \mathrm{~g}$ & $1.22 \pm 0.035 \mathrm{ml}$ & 0.055 \\
\hline
\end{tabular}

${ }^{*} p<0.05$ compared to CD26/DPP4- pups

Carolina, USA). Statistical differences were determined with the two-factorial ANOVA (two-way analysis of variance) with the factors strain and treatment as discriminatory factors. When statistically significant, starting at $p<0.05$, a separation was made to the one-way analysis of variance (ANOVA) followed by a Fisher-PLSD post hoc analysis.

\section{Results}

\section{Body weight and lung volume}

\section{Controls}

Both substrains exhibited a comparable body weight on dpp 7, which continuously increased on dpp 10 and 14 independent of the substrain. Lung volume in both substrains also increased; however, it was significantly higher in the $\mathrm{CD}^{2} 6^{+}$group compared to CD26- pups on dpp 7 and $\mathrm{dpp}$ 10 (Table 3 ). The lung volume body weight ratio as additional measure of immaturity (De Paepe et al. 2005, 2014) was somewhat lower in $\mathrm{CD}_{2} 6^{-}$controls than in $\mathrm{CD}_{2} 6^{+}$pups (Table 3).

Table 4 ANOVA two-way analyses, tabular results

\section{LPS exposure for 7 days}

Chronically applied LPS resulted in a more pronounced significant increase of body weight in $\mathrm{CD}^{2} 6^{+}$pups than in CD26- pups compared to controls only on dpp 7 (Table 3 ). Lung volume was not influenced by LPS on dpp 7, 10, and 14 . The lung body weight ratio was only notably lower noteworthy on dpp 7 compared to controls independent of the substrain (Table 3).

ANOVA two-way analyses exhibited that body weight and lung volume were influenced by the treatment, but not by the genotype. However, the genotype had the same effect as the treatment-dependent values on dpp 7 (Table 4). The genotype affected the values on dpp 14 (Table 4).

\section{CD11 positive inflammatory cells in lung parenchyma}

To obtain some information about the parenchymal inflammation, we carried out labeling with the surface marker B_2integrin CD11b.

\begin{tabular}{llllllll}
\hline & Body weight & Lung volume & Ssepta & Vsepta & Vairspace & MLI & Septal thickness \\
\hline Dpp 7 & & & & & & & \\
Genotype & n.s & n.s & 0.0091 & 0.0012 & 0.0131 & n.s & n.s \\
Treatment & 0.0001 & 0.0001 & 0.0003 & 0.0168 & n.s & 0.0002 & n.s \\
Interaction & 0.0002 & 0.0002 & n.s & n.s & n.s & n.s & n.s \\
Dpp 10 & & & & & & & \\
Genotype & n.s & 0.0001 & 0.0001 & 0.001 & 0.0001 & 0.1121 & 0.1324 \\
Treatment & n.s & n.s & 0.0139 & 0.0013 & 0.2173 & 0.0247 & 0.0088 \\
Interaction & n.s & n.s & n.s & n.s & 0.1183 & 0.1755 & n.s \\
Dpp 14 & & & & & & & \\
Genotype & 0.0006 & 0.0001 & 0.0005 & 0.01 & n.s & 0.1962 & n.s \\
Treatment & 0.0318 & n.s & n.s & 00.0463 & n.s & 0.1572 & n.s \\
Interaction & n.s & n.s & n.s & n.s & n.s & 0.0663 & n.s \\
\hline
\end{tabular}




\section{Controls}

CD11 positive inflammatory cells were barely visible (Fig. 1). Using cell profile density as a quantitative parameter, only a few CD11-positive granulocytes and macrophages were determined. There were no subtype specific differences (Table 5).

\section{LPS exposure for 7 days}

In the lungs of the animals exposed to LPS, there was a very mild inflammatory reaction with evidence of immigrated CD11b-positive macrophages and neutrophil granulocytes. However, in both subtypes, the cell profile density of macrophages increased only slightly in both groups (Fig. 1).

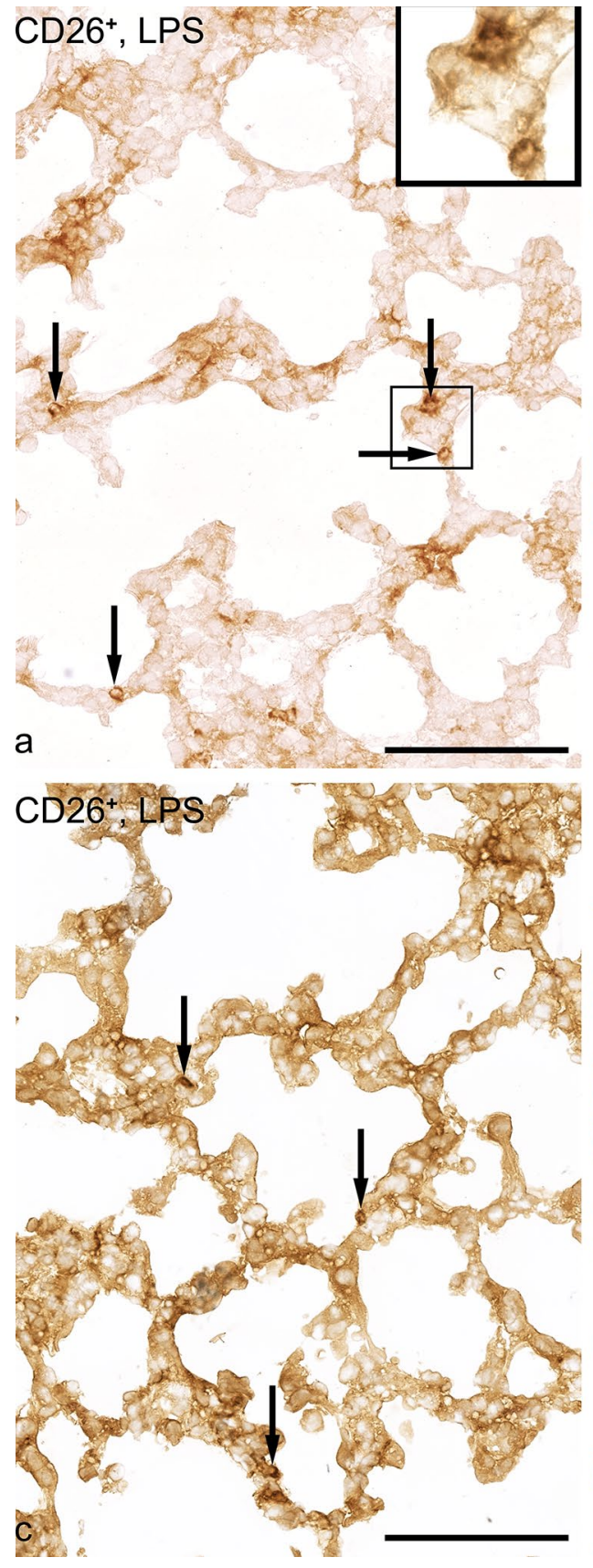

Fig. 1 Immunohistochemically labeled inflammatory cells indicated by arrows using the avidin biotin complex method to detect the $\beta 2$-integrin $\mathrm{CD} 11 \mathrm{~b}$ as surface marker. Inflammatory cells in lungs of 7- and 10-day-old lungs in both genotypes after LPS expo-

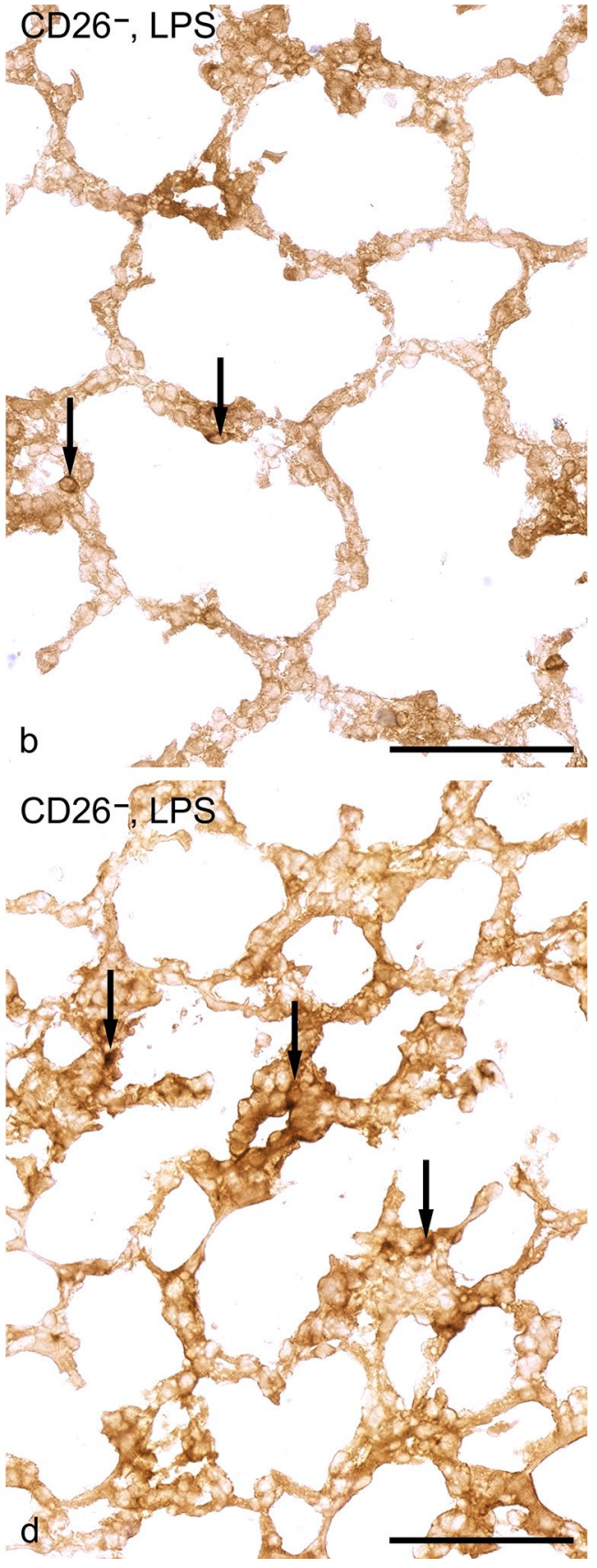

sure are rarely found: a CD26 $6^{+}$dpp $7($ bar $=100 \mu \mathrm{m}), \mathbf{b ~ C D}{ }^{-} \mathrm{dpp}$ $10(\mathrm{bar}=100 \mu \mathrm{m}), \mathbf{c} \mathrm{CD} 26^{+}$, dpp7 $\left(\mathrm{bar}=100 \mu \mathrm{m}, \mathbf{d ~ C D} 26^{-} \mathrm{dpp} 10\right.$ $(\mathrm{bar}=100 \mu \mathrm{m})$ 
Table 5 Cell profile densities of CD11b labeled inflammatory cells

\begin{tabular}{|c|c|c|c|c|c|}
\hline Genotype & & $\mathrm{CD}^{26 / \mathrm{DPP}} 4^{+}$ & & CD26/DPP4- & \\
\hline mean \pm SEM & & cells $/ \mathrm{mm}^{2}$ & & cells $/ \mathrm{mm}^{2}$ & \\
\hline dpp & Inflammatory cells & Controls & LPS & Controls & LPS \\
\hline 7 & Neutrophils & $2.3 \pm 0.4$ & $14.7 \pm 1.5^{*}$ & $2.6 \pm 0.7$ & $10.3 \pm 3.7 *$ \\
\hline \multirow[t]{3}{*}{10} & Macrophages & $0.7 \pm 0.5$ & $2.0 \pm 1.4$ & $0.1 \pm 0.0$ & $0.5 \pm 0.0$ \\
\hline & Neutrophils & $1.9 \pm 0.1$ & $16.5 \pm 4.0 *$ & $3.1 \pm 2.2$ & $11.7 \pm 0.2^{*}$ \\
\hline & Macrophages & $0.4 \pm 0.2$ & $4.6 \pm 0.7$ & $0.5 \pm 0.0$ & $1.5 \pm 1.5$ \\
\hline
\end{tabular}

Significantly increased cell profile densities of neutrophils were found in both groups on dpp 7 and dpp 10 without significant subtype differences (Table 5).

\section{Qualitative morphology}

\section{Controls}

Wild-type controls exhibited a morphology corresponding to the stage of development. Qualitatively, only slight differences between $\mathrm{CD} 26^{+}$and $\mathrm{CD} 26^{-}$pups were visible. On dpp 7, previously smooth-walled primary septa were sprouting in many places (Figs. 2a and 3a). From these "buds," the so-called secondary septa were visible, drawn into the expanding air spaces and thus represented the boundary of the future alveoli. On dpp 10, the rat lungs were in the middle of alveolarization (Figs. 2c and 3c). Compared to dpp 7, the bronchial tree had branched out more, so that many new air spaces had arisen. On dpp 14, at the end of the bulk alveolarization phase, a lot of small alveoli were visible in the lungs. The lung parenchyma contained numerous alveoli (Figs. 2e and 3e).

\section{LPS exposure for 7 days}

On dpp 7, the airspaces were still relatively large, and the sprouts of the secondary septa were seen less frequently compared to controls independent of the CD26 expression (Figs. 2a,b and 3a,b). However, the septa looked intact. Newly formed septa had not been destroyed. Qualitative differences in the degree of maturation were barely visible between the two substrains. The terminal airspaces showed less sprouts as a sign of the beginning of septation and seemed to be somewhat larger in the CD26-deficient group (Figs. $2 \mathrm{~b}$ and $3 \mathrm{~b}$ ). On dpp 10, newly formed alveoli were seen in both strains, and the number of sprouts had increased (Figs. 2d and 3d). Also, no signs of destruction of the septa were visible. Lungs on dpp 14 showed a further increase in newly formed alveoli without recognizable substrain-specific differences (Figs. 2f and 3f).

\section{Bronchi and peribronchial spaces}

Controls of both groups showed no inflammatory cells around bronchi or vessels.

After LPS exposure, clearly visible signs of inflammation in the bronchial wall or in the peribronchial space were not detected in both groups on dpp 7or on dpp 10.

\section{Stereological parameters}

\section{Controls}

The results showing significantly lower values of $S$ (septa, lung), $V$ (septa, lung), $V$ (airspace, lung) in lungs of $\mathrm{CD} 26^{-}$pups compared to $\mathrm{CD} 26^{+}$pups on dpp 7 and 10 should be mentioned here (Figs. 4 and 5). These have already been published (Wagener et al. 2020).

\section{LPS exposure for 7 days}

The $S$ (septa, lung) as an indirect parameter for alveolarization was significantly lower on dpp 7 and in the CD26- group also on dpp 10 in both substrains compared to controls, meaning that LPS reduced the formation of secondary septa. On dpp 14, comparable $S$ (septa, lung) were determined in $\mathrm{CD} 26^{+}$pups; however, in $\mathrm{CD} 26^{-}$pups, the reduced total septal surface still remained significantly lower (Fig. 4a, c, e).

The $V$ (septa, lung) was significantly lower compared to control values on dpp 10 in the $\mathrm{CD} 26^{+}$group and on dpp 7 and 10 in the $\mathrm{CD} 26^{-}$group. Both substrains showed similar values compared to controls on dpp 14 (Fig. 4b, d, f).

The volume of parenchymal airspaces was higher compared to controls, but reached significance only in the CD26- group (Fig. 5a, c, e). Significantly lower values were determined on dpp 10 in both groups compared to controls. No differences were seen on dpp 14. MLI, a measure of the mean free distances in airspaces, was higher after LPS exposure in both substrains on dpp 7 and dpp 10 (Fig. 5b, d, f).

The arithmetic mean septal thickness was not influenced by LPS exposure compared to controls. The arithmetic mean 


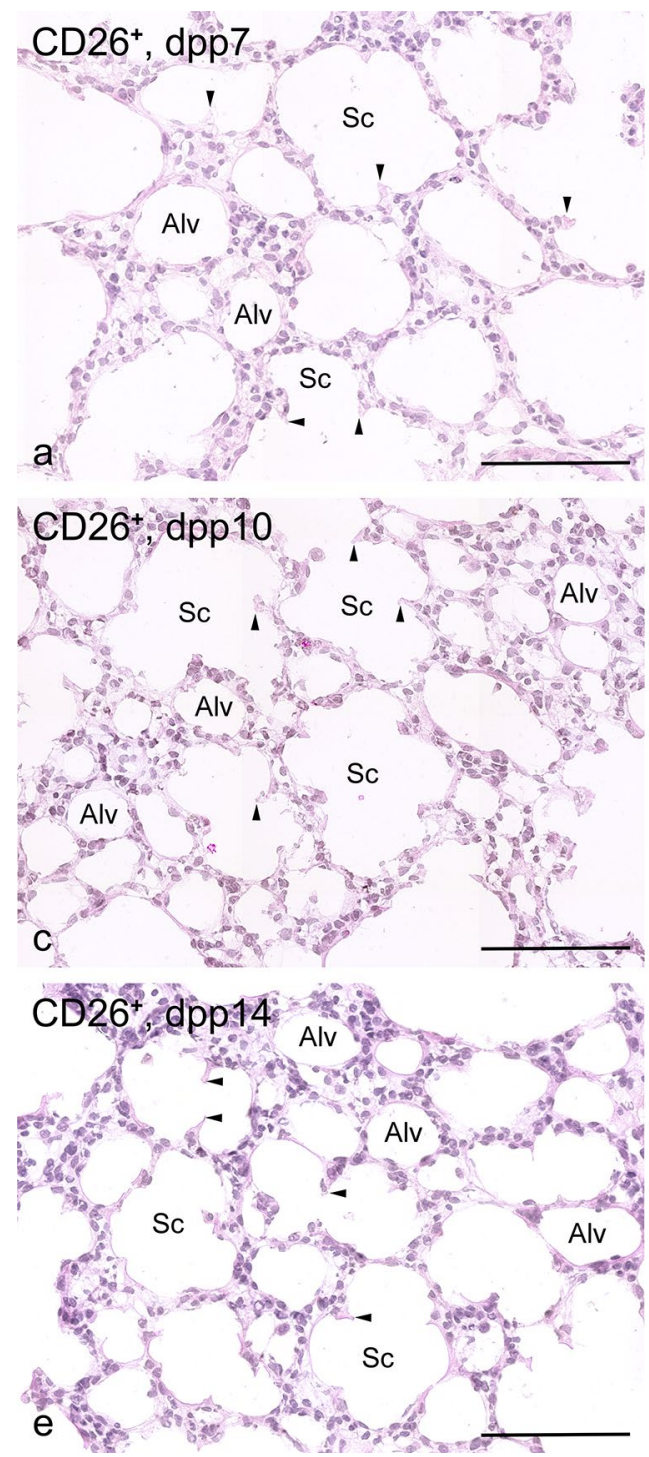

Fig. 2 Morphological lung development without and with LPS exposure in $\mathrm{CD}_{2} 6^{+}$pups (bar $\left.=100 \mu \mathrm{m}\right)$. a Control, $7 \mathrm{dpp}$ : lung parenchyma exhibit smooth-walled primary septa and numerous so called secondary septa ( arrow heads) are formed, extending into the expanding air spaces. (Alv =alveolus, $\mathrm{Sc}=$ Sacculus) $\mathbf{b}$ LPS exposure, $7 \mathrm{dpp}$ : airspaces are still relatively large, and the sprouts of the secondary septa (arrow heads) are seen less frequently in lung parenchyma. Alveolar septa are structurally intact. (Alv=Alveolus, $\mathrm{Sc}=$ Sacculus). c Control, $10 \mathrm{dpp}$ : multiple smaller airspaces formed by secondary septation (arrow heads).

septal thickness was $13.3 \pm 0.4 \mu \mathrm{m}$ in the $\mathrm{CD} 26^{+}$group compared to $13.2 \pm 0.8 \mu \mathrm{m}$ on $\mathrm{dpp} 7,10.7 \pm 0.4 \mu \mathrm{m}$ compared to $12.2 \pm 0.6 \mu \mathrm{m}$ on $\mathrm{dpp} 10$, and $10.5 \pm 0.5 \mu \mathrm{m}$ compared to $11.0 \pm 0.1 \mu \mathrm{m}$ on dpp 14. In the CD26-deficient group, the arithmetic mean septal thickness amounted to $12.5 \pm 1.0 \mu \mathrm{m}$ compared to $13.1 \pm 1.1 \mu \mathrm{m}$ on dpp 7 , to $11.4 \pm 1.1 \mu \mathrm{m}$ compared to $12.4 \pm 0.9 \mu \mathrm{m}$ on dpp 10 and to $11.0 \pm 0.6 \mu \mathrm{m}$ compared to $11.1 \pm 0.1 \mu \mathrm{m}$ on $\mathrm{dpp} 14$.

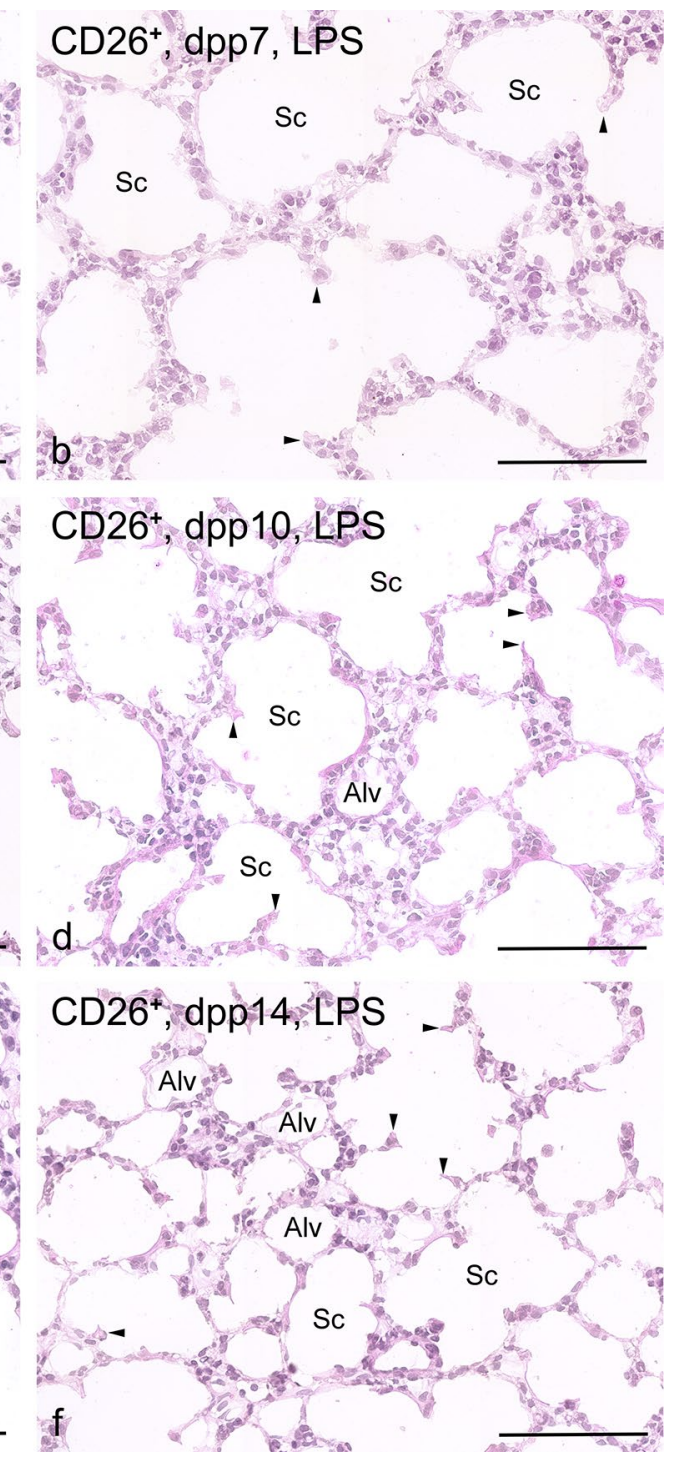

(Alv=Alveolus, $\mathrm{Sc}=$ Sacculus). $\mathbf{d}$ LPS exposure, $10 \mathrm{dpp}$ : newly formed septa are visible, the number of sprouts (arrow heads) is less frequent, and no signs of destruction of the septa are recognizable. (Alv=Alveolus, $\mathrm{Sc}=$ Sacculus). e Control, $14 \mathrm{dpp}$ : numerous small alveoli (Alv) in the lung parenchyma are visible. $(\mathrm{Alv}=$ Alveolus, $\mathrm{Sc}=$ Sacculus, arrow head $=$ secondary septa). f LPS exposure, $14 \mathrm{dpp}$ : a further increase in newly formed intact alveoli (Alv) is seen. (Alv $=$ Alveolus, $\mathrm{Sc}=$ Sacculus, arrow head $=$ secondary septa)

Looking at the tabular results of the two-way ANOVA tests (Table 4), we could summarize that the parameters Ssepta and Vsepta were significantly influenced by genotype and treatment on dpp 7 and dpp 10. On dpp 14, only the genotype affected the results significantly (Table 4). However, the impact of the treatment was independent of the genotype (Table 4). Vairspace was significantly influenced by the genotype on dpp 7 and dpp 14, and MLI was 


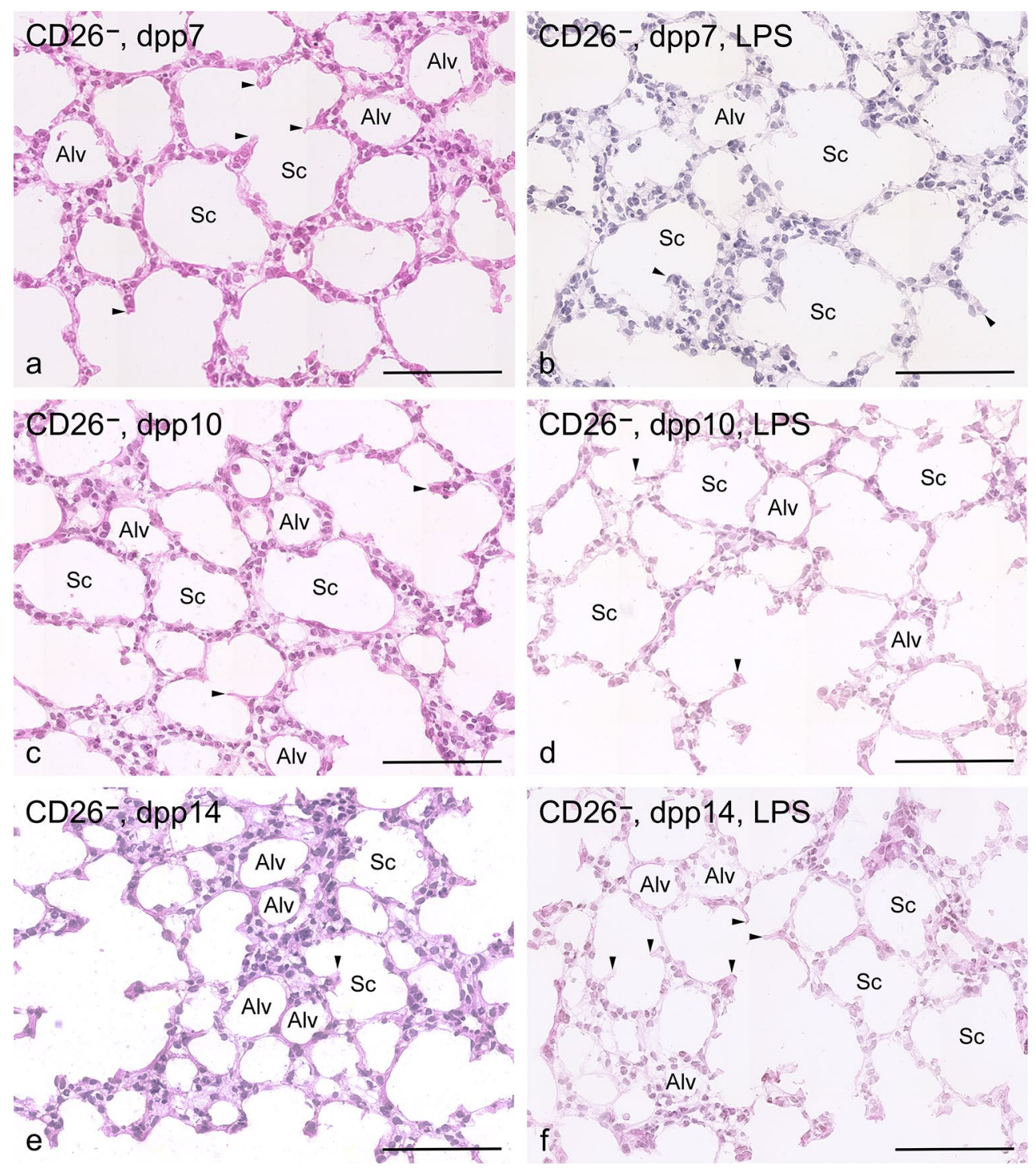

Fig. 3 Morphological lung development without and with LPS exposure in CD26- lungs (bar $=100 \mu \mathrm{m})$ : a Control, $7 \mathrm{dpp}$ : sacculi and some socalled secondary septa are visible. $(\mathrm{Alv}=$ Alveolus, $\mathrm{Sc}=$ Sacculus, arrow head $=$ secondary septa). b LPS exposure, $7 \mathrm{dpp}$ : sacculi predominate in the lung parenchyma. Alveoli are sporadically seen. Alveolar septa are structurally intact. (Alv $=$ Alveolus, $\mathrm{Sc}=$ Sacculus, arrow head $=\mathrm{sec}-$ ondary septa), c Control, $10 \mathrm{dpp}$ : newly formed alveoli are found between sacculi. No signs of destruction of the septa are recognizable.

significantly influenced by the treatment on dpp 7 and dpp 10 , the arithmetic mean septal thickness by the treatment on dpp 10.

Summarizing our results, LPS-induced effects were detectable in both strains on the dpp 7. This showed up in the form of a reduced septa surface and septal volume fraction, as well as an increase in the absolute volume of the air space and an increase of MLI as a measure of the mean free distances in airspaces. The substrain-specific differences already described for the control animals remained. Also on
$($ Alv $=$ Alveolus, $\mathrm{Sc}=$ Sacculus, arrow head $=$ secondary septa $) . \mathbf{d}$ LPS exposure, 10 dpp: newly formed alveoli are sporadically recognizable. e Control, 14 dpp: many alveoli are seen. (Alv=Alveolus, $\mathrm{Sc}=$ Sacculus, arrow head $=$ secondary septa). f LPS exposure, 14dpp: several larger alveoli and sacculi with sprouting short secondary septa are visible. $(\mathrm{Alv}=$ Alveolus, $\mathrm{Sc}=$ Sacculus, arrow head $=$ secondary septa $)$

dpp 10, LPS effects were demonstrated in both strains on postnatal morphological pulmonary maturation as a decrease in the absolute septal volume, a related increase in the absolute volume of the airspace, increased MLI as a measure of the mean free distances in airspaces and narrower septa. The LPS-dependent differences remained in terms of volumes and septa surface. However, LPS-induced changes were no longer detectable in the wild-type animals on the dpp 14, although a reduced septal surface was still detectable in the CD26-deficient animals. 
Fig. 4 Stereologically determined parameters exhibiting morphological lung maturation, given as mean $\pm \mathrm{SD}$ : total septal surface, serving as a parameter indicating alveolar septation as an indirect measure for alveolarization: a pups of dpp7 ( $n=3$ /group), $\mathbf{c}$ pups of dpp10 ( $n=3 /$ group), e pups of dpp 14 ( $n=3$ /group); total septal volume, taken as a parameter for the volume of primary and newly formed septa, without considering their thickness: $\mathbf{b}$ pups of dpp7 ( $n=3 /$ group), $\mathbf{d}$ pups of dpp10 ( $n=3 /$ group), $\mathbf{f}$ pups of dpp 14 ( $n=3$ /group)
Total septal surface
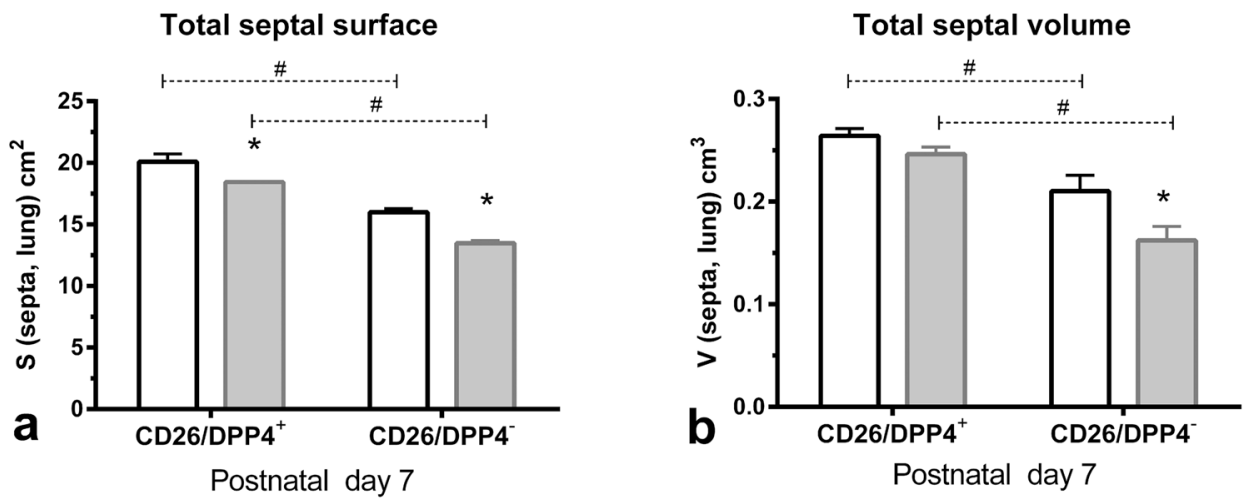

Controls

Exposed to LPS

Total septal surface

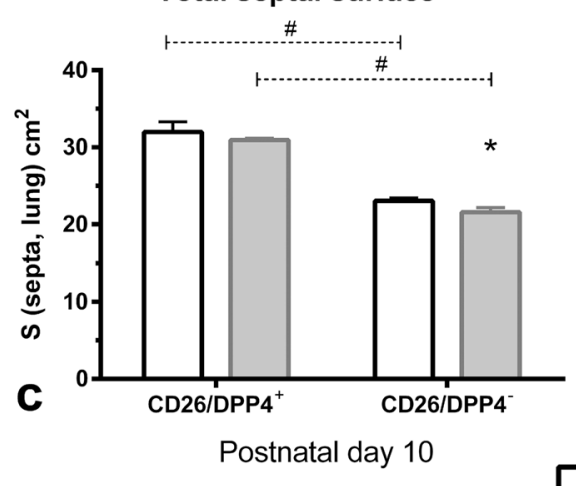

Controls

Exposed to LPS
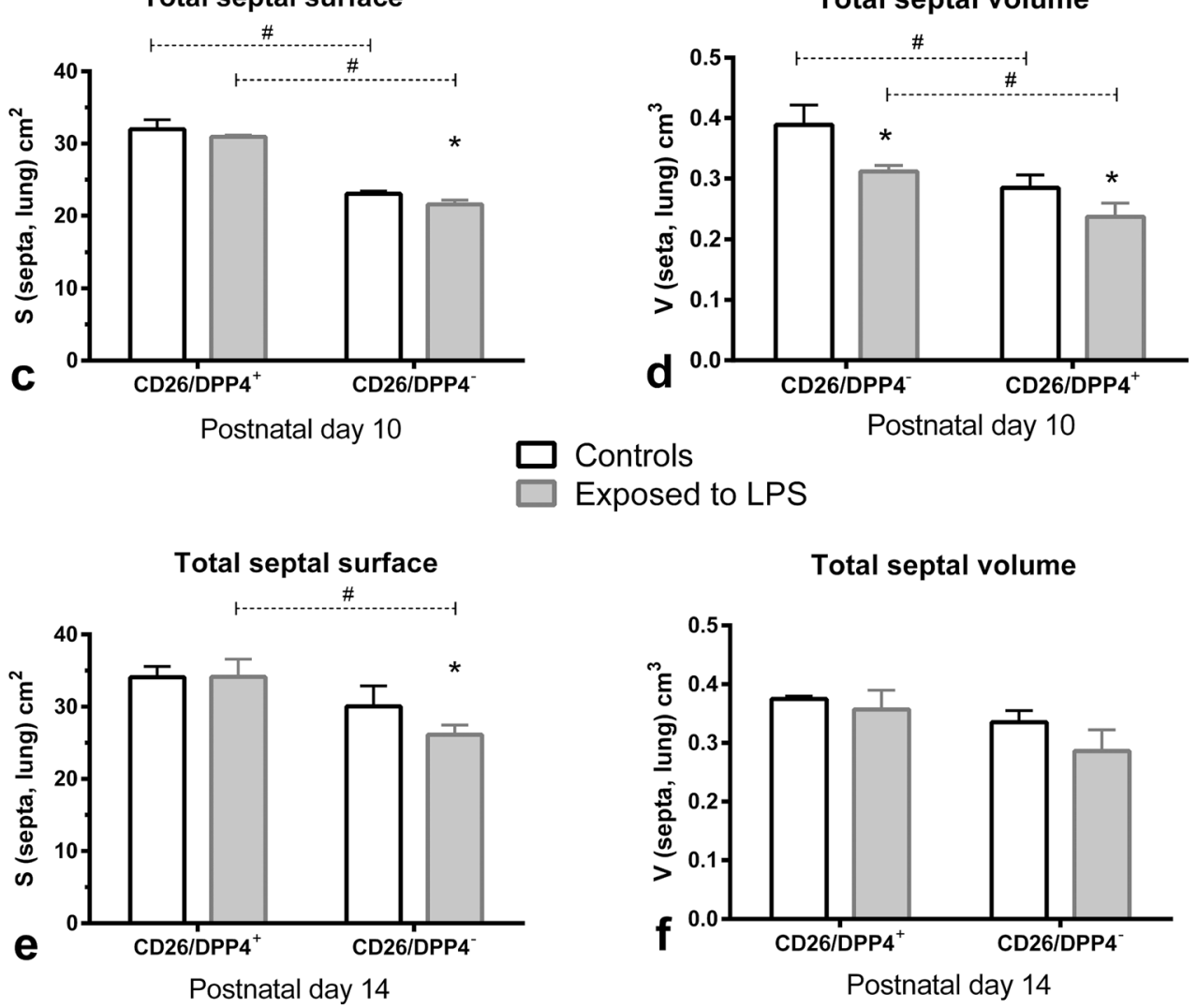

Total septal volume

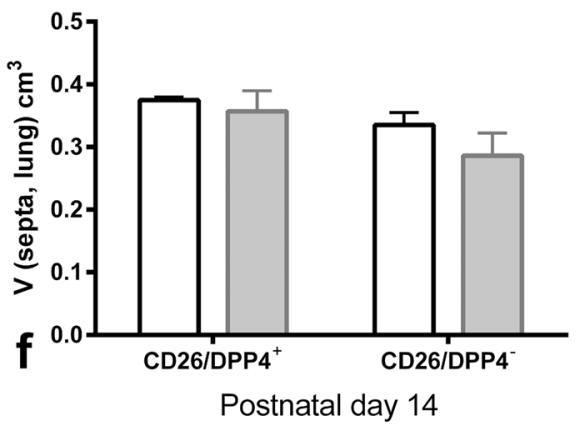

\section{Characterization of immune cells}

\section{Controls}

To obtain some information about the influence of CD26 on the immunological status in both substrains, we determined the composition of immunological cells using FACS analyses and stated the results as percentage of total leucocytes in lung homogenates. Absolute cell numbers are listed in Table 6. Because of the variation in absolute cell numbers, the percentage of immune cells was used for comparisons (Table 7).
The percentage of monocytes was significantly lower in controls of $\mathrm{CD} 26$ deficient rats.

Looking at the percentage of lymphocytes, no substrain or developmental dependent differences existed on dpp 7. However, lower percentages of lymphocytes were found on dpp 10 and dpp 14 in CD26- pups reaching significance only on dpp 10 (Table 7). The B lymphocytes showed no straindependent differences. To check whether there is an increase in the portion of $\mathrm{T}$ cell subpopulations that may produce maturation-relevant cytokines, different T-cell subpopulations were studied. Interestingly, in the controls, we found remarkable higher values of $\mathrm{T}$ lymphocytes in $\mathrm{CD} 26^{-}$rats 
Fig. 5 Total volume of airspaces of sacculi/alveoli, serving as a parameter for enlargement or reduction of airspaces, given as mean \pm SD: a pups of dpp7 ( $n=3 /$ group), c pups of dpp10 ( $n=3 /$ group), e pups of dpp 14 ( $n=3$ /group). Size of saccui/alveoli, a size parameter independent of the reference space b pups of dpp $7(n=3 /$ group), d pups of dpp $10(n=3 /$ group), f pups of dpp $14(n=3 /$ group)
Total volume of parenchymal airspaces

Mean linear intercept
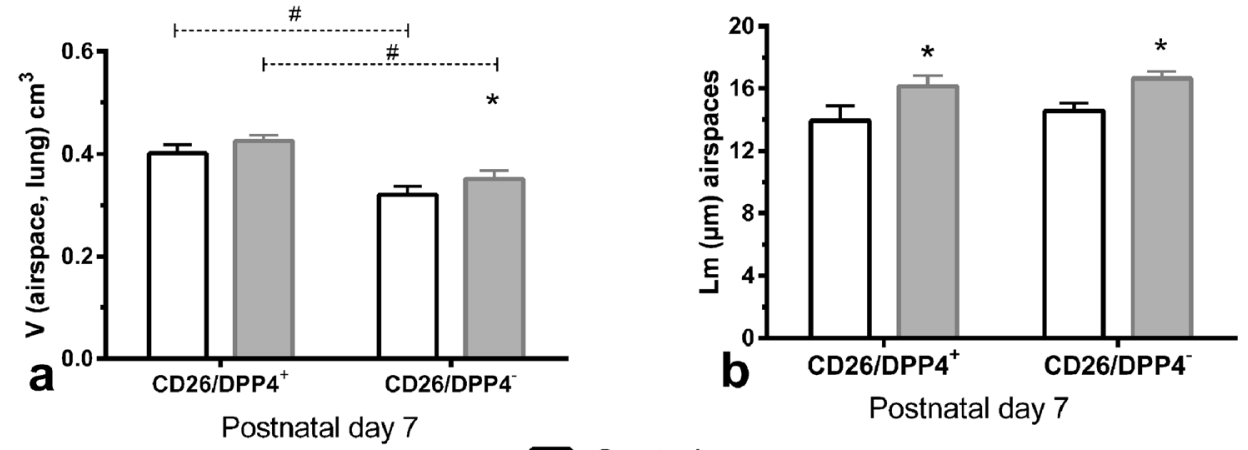

Controls

Exposed to LPS

Total volume of parenchymal airspaces

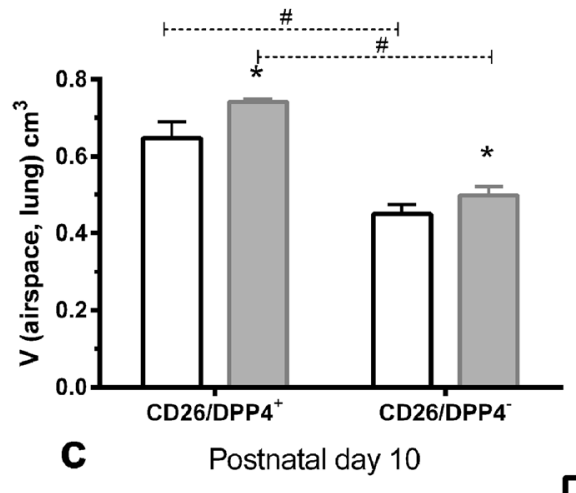

Controls

Exposed to LPS

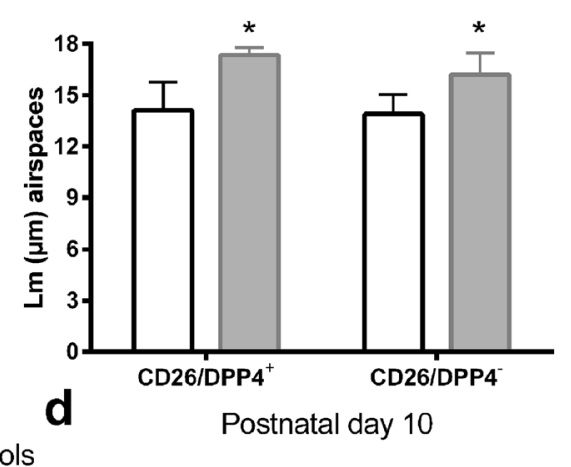

Total volume of parenchymal airspaces

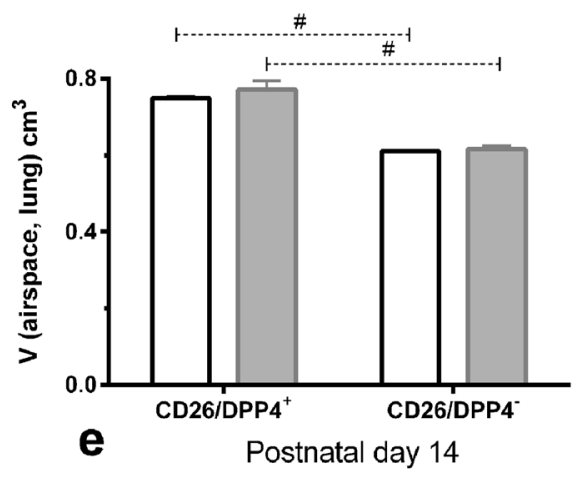

Mean linear intercept

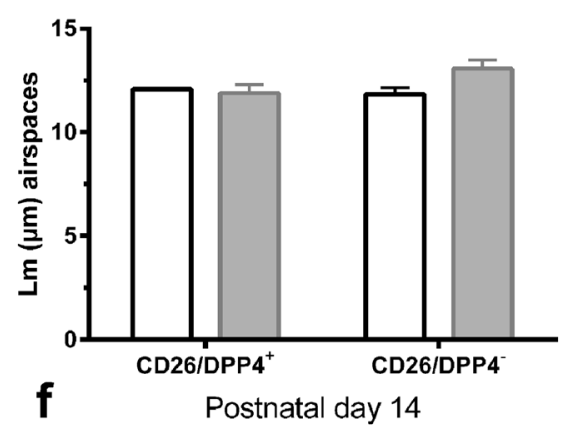

compared to $\mathrm{CD} 26^{+}$rats, reaching significance on dpp 7 . Both groups showed comparable values of $\mathrm{CD}^{+} \mathrm{T}$ cells (Table 7). The percentage of $\mathrm{CD}^{+} \mathrm{T}$ cells was significantly higher in the $\mathrm{CD} 26^{-}$group on dpp 7 and dpp 14 (Table 7). The $\mathrm{CD} 4^{+} / \mathrm{CD} 25^{+} \mathrm{T}$ cells containing the activated and the regulatory $\mathrm{T}$ cells were significantly higher on each postnatal day in the $\mathrm{CD}_{2} 6^{-}$compared to the $\mathrm{CD} 26^{+}$pups (Table 7 ). The percentage of monocytes was significantly lower in the CD26-deficient group on dpp 7, dpp 10, and dpp 14 compared to $\mathrm{CD} 26^{+}$pups. Thus, we found some strain-dependent differences in the population of leucocytes in controls.

\section{LPS exposure for 7 days}

In order to check whether the differential influence of LPS on lung morphogenesis is also seen in the leukocyte composition and thus the inflammatory reaction to the LPS stimulus, FACS analyses of lung homogenates were additionally performed.

The percentage of monocytes was influenced by LPS only on dpp 7 (Table 7).

When looking at all lymphocytes, no effects were found on the dpp 7. While on dpp 10 and dpp 14, significant 

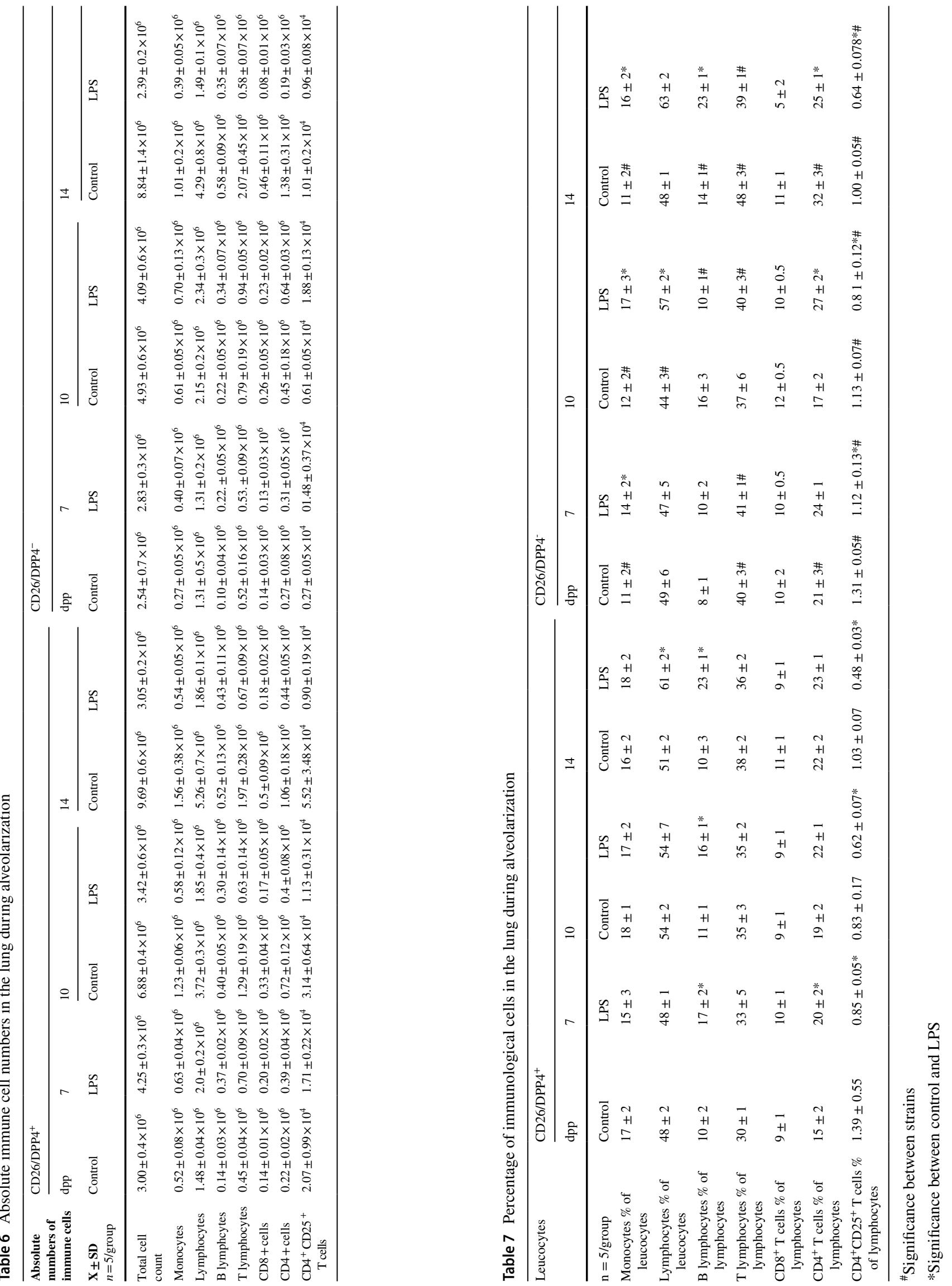
increases in the percentage of lymphocytes were determined in both substrains. On dpp 10, there was an increase of 3\% in wild-type rats and 13\% in CD26-deficient rats. On dpp 14, the proportion of lymphocytes in wild-type rats increased by $11 \%$, in CD26-deficient rats by $15 \%$ (Table 7).

We found a significant increase of B lymphocytes on dpp7 and dpp 14 in both substrains and on dpp 10 and dpp 14 in $\mathrm{CD} 26^{+}$pups. LPS did not influence T lymphocytes in their percentages. However, compared to $\mathrm{CD} 26^{+}$pups, the percentage of $\mathrm{T}$ lymphocytes was significantly higher in the CD26- pups on each dpp (Table 7). Compared to controls, the percentage of $\mathrm{CD} 4^{+} \mathrm{T}$-cells was significantly increased on dpp 7 in the $\mathrm{CD} 26^{+}$group and on dpp 10 in the $\mathrm{CD} 26^{-}$group. No effects were detectable on dpp 14 (Table 7). The $\mathrm{CD} 4^{+} / \mathrm{CD} 25^{+} \mathrm{T}$-cells, which contained regulatory T-cells, were significantly lower compared to controls in the $\mathrm{CD} 26^{+}$group not only on dpp 7, but also on dpp 10 and dpp 14 independent of the substrain.

ANOVA two-way analyses showed that the percentage of monocytes and T-cells was influenced by the genotype during all postnatal developmental stages. Treatment influenced the percentage of $\mathrm{CD}^{+}$and $\mathrm{CD} 4^{+}$cells at all time points investigated (Table 8). Combined effects of genotype and treatment were seen for monocytes on dpp7 and dpp 10, for lymphocytes on dpp10, for B-cells on dpp7, for T-cells on dpp 14 (Table 8).

\section{Validation of CD26 deficiency}

The absence of CD26 in the CD26 deficient rat group has been already proved in several publications (Zientara et al. 2019; Karl et al. 2003; Kruschinski et al. 2005; Schade et al. 2008). To verify additionally the CD26 deficiency during postnatal development in lungs, we determined the content of $\mathrm{CD} 26^{+} \mathrm{CD} 4^{+}$cells (Table 9). In the deficient rat lungs, no $\mathrm{CD} 26^{+}$cells were found. LPS application did not change the $\mathrm{CD} 26^{+} \mathrm{T}$ cells in the $\mathrm{CD} 26^{+}$pups.
In the CD26- pups, the CD26-T cells were significantly increased compared to controls on dpp 10 and dpp 14 (Table 9).

\section{Discussion}

Compared to CD26/DPP4 ${ }^{+}$wild types, CD26 deficiency led to comparable body weights, but to significantly lower lung volumes and significantly lower total septal surface, septal volume, and parenchymal airspace volume on dpp 7 and dpp 10. However, the lung (weight) volume to body weight ratio, determining the lung growth in relation to body weight as an indirect measure for immature lungs (De Paepe et al. 2014, 2005), exhibited no significant LPSdependent differences during postnatal development. Thus, our LPS model does not lead to remarkable delay in lung growth.

Regarding the immune status in CD26-deficient pups, significantly higher percentages of $\mathrm{T}$ cells and $\mathrm{CD} 4^{+} \mathrm{T}$ cells were found on dpp 7 as well as significantly higher percentages of $\mathrm{CD} 4^{+} \mathrm{CD} 25^{+} \mathrm{T}$ cells and significantly lower percentages of monocytes.

The maturing lung is particularly at risk of being damaged by external influences. In addition to the structural immaturity of the respiratory system, the immune system is not yet fully developed in the fetal compared to the adult lung (Martin and Frevert 2005; Anderson 2000). The nebulization of LPS dissolved in physiological common salt as application method enables precise dosing. It also represents a very gentle method for the animals, since they hardly need to be manipulated, and they can remain together as a litter. This method is therefore well suited for multiple applications over a period of several days. The disadvantage of this form of application is that the aerosol may not only be absorbed via the lungs, but over the entire body surface.
Table 8 ANOVA two-way analyses, tabular results

\begin{tabular}{lllllllll}
\hline & Monocytes & Lymphocytes & B-cells & T-cells & CD8 ${ }^{+}$cells & CD4 $^{+}$cells & CD4 ${ }^{+}$CD25 $5^{+}$cells \\
\hline Dpp 7 & & & & & & & \\
Genotype & 0.0001 & n.s & 0.024 & 0.0001 & n.s & 0.0004 & 0.205 \\
Treatment & n.s & 0.1328 & 0.009 & n.s & 0.0238 & 0.0043 & 0.025 \\
Interaction & 0.0001 & n.s & n.s & n.s & 0.2004 & n.s & n.s \\
Dpp 10 & & & & & & & \\
Genotype & 0.0001 & 0.0761 & 0.0001 & 0.023 & 0.0928 & 0.03 & 0.0001 \\
Treatment & 0.002 & 0.0017 & n.s & 0.081 & 0.0516 & 0.0001 & 0.0001 \\
Interaction & 0.0001 & 0.0014 & 0.0001 & n.s & 0.0928 & 0.028 & 0.0001 \\
Dpp 14 & & & & & & & \\
Genotype & 0.0057 & n.s & 0.152 & 0.0001 & n.s & n.s & n.s \\
Treatment & 0.0032 & 0.0002 & 0.0001 & 0.0001 & 0.03 & 0.0001 & 0.0008 \\
Interaction & 0.1309 & 0.1083 & 0.0141 & 0.0036 & n.s & 0.0001 & n.s \\
\hline
\end{tabular}




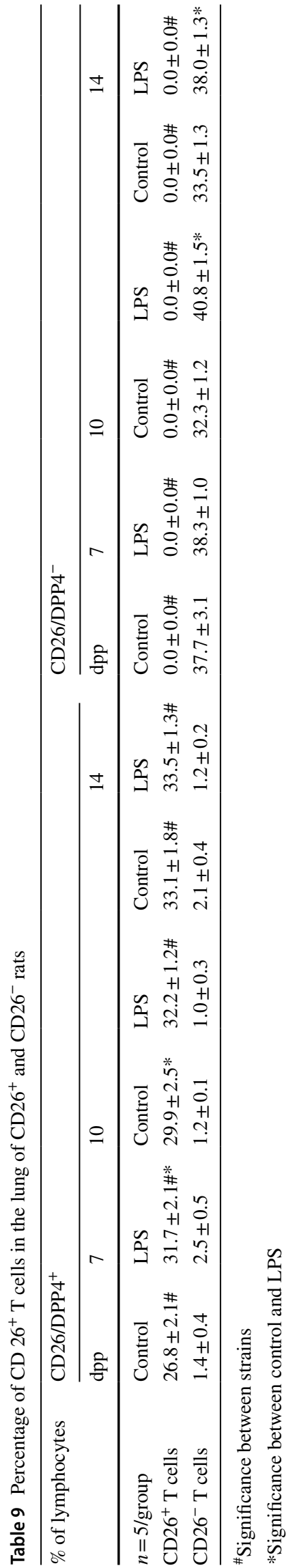

\section{Measurement of retarded lung maturation}

To determine the lung volume, we used the water displacement method (Scherle 1970). Because of the small size of lungs, a lack of precision using the Archimedes principle was postulated (Pozarska et al. 2017). We always measured both lungs and accurately dried the lobes and dapped off the water droplets in the interlobar regions. Doing so, the variation of lung volume within the investigated groups was in a tolerable range, and the population coefficient of variation was in all cases lower than $10 \%$.

There are different ways to analyze alveolarization. Often, the radial alveolar counts (RACs) were determined (Dasgupta et al. 2009; Dauger et al. 2003; Husain et al. 1998; Shrestha et al. 2019; Cooney and Thurlbeck 1982a). The RAC reflects the number of alveoli per unit area as a measure of complexity of the terminal respiratory unit (acinus). It gives no information about the total number of alveoli or alveoli per unit volume (Cooney and Thurlbeck 1982b, 1982a). The RAC method shows an indirect correlation to numbers of alveoli (Herring et al. 2014). Mean linear intercepts (MLI) were also used to determine lung maturation, because this method may be suitable for determining the size of airspaces (Husain et al. 1998; Manzano et al. 2014; Tiono et al. 2019). However, MLI do not really measure alveolar size as often argued (Ochs 2014). MLI measure the mean free distance between walls of acinar spaces (Knudsen et al. 2010). Furthermore, values of MLI depended on the degree of normal lung inflation (Ochs 2014). To determine morphological lung maturation, we therefore used single-section parameters which characterize predominantly the parenchymal compartments. Using the point and intersection counting method together with the known lung volume, the determined parameters give sufficient information about the total amount of airspace and septa as well as the total septal surface area (Ochs 2014; Schmiedl et al. 2017; Wagener et al. 2020; Hupa et al. 2014). The increase of septal surface is an indirect indication for new secondary septa and therefore of alveolarization. Furthermore, the surface area correlates very well with the total gestation age (Cooney and Thurlbeck 1982b). The determination of the total septal volume and the total airspace volume in combination with the total surface area permits estimation of the architecture of the developing lung parenchyma.

However, our investigations were carried out on frozen lungs and frozen sections. Therefore, we cannot rule out the influence of strain and/or treatment-dependent shrinkage on the parameters used.

\section{Determining the immune status}

We presented the percentage distribution of immune cells to avoid inaccuracies caused by problems in the determination of total numbers of cells resulting in great variations. In the 
present work, FACS analyses were firstly carried out on the lungs of rat juveniles to also compare substrain-dependent differences.

\section{CD26 and immune status}

CD26 cleaves not only several cytokines and chemokines as well as peptide hormones involved in the regulation of the immune system but also modulates lymphocyte function (Broxmeyer et al. 2016; Proost et al. 2000;Klemann et al. 2016; Van et al. 1999; Shao et al. 2020). So, it is involved in the costimulation of $\mathrm{T}$ cells (Ohnuma et al. 2008) and may influence transepithelial T cell migration (Shao et al. 2020). The degree of $\mathrm{CD} 26$ expression on $\mathrm{CD} 4^{+} \mathrm{T}$ cells additionally influences the behavior of these cells (Shao et al. 2020). A higher expression of CD26 results in a Th1-like helper phenotype combined with the secretion of inflammatory cytokines such as interferon $\gamma$ (INF $\gamma$ ) and interleukin 2 (IL2) and activation of macrophages, CD8 cells, whereas low expression is accompanied with the TH2-phenotype combined with a secretion of IL 4, IL 5, IL 10, TGF $\beta$, and activation of $\mathrm{CD}^{+}$cells with stimulation of $\mathrm{B}$ lymphocytes (Reinhold et al. 1997; Shao et al. 2020). Looking at the immune cells, these findings are partly comparable with our results. So, we evaluated generally partly significantly higher percentages of $\mathrm{CD}^{+} \mathrm{T}$ cells in the $\mathrm{CD} 26^{-}$group during postnatal development.

Furthermore, CD26 was also seen on the surface of other immune cells such as B cells, dendritic cells, and macrophages as summarized by Shao et al. (Shao et al. 2020; Buhling et al. 1995). Preliminary investigations by our group had shown that there are differences in the composition of immune cells in adult animals in a strain comparison and that CD26 deficiency leads to a change in the hematopoietic maturation of immune cells in the thymus (Klemann et al. 2009). However, in young animals at 1 and 3 months of age, there were no differences in leucocyte subsets, while in older animals, the $\mathrm{T}$ cell composition was changed significantly. Interestingly, there were no substrain-specific differences in the total number of $\mathrm{CD}^{+}$and $\mathrm{CD}^{+}$cells either in the peripheral blood or in the spleen (Klemann et al. 2009), whereas in the present study, there was a significantly higher percentage of $\mathrm{CD} 4^{+} \mathrm{T}$ cells in the $\mathrm{CD} 26^{-}$animals on dpp 7 and dpp 14. In contrast, significant differences in the total number of $\mathrm{CD}^{+} \mathrm{T}$ cells were also shown in a mouse model with CD26 knockout animals using splenic lymphocytes. Here, higher cell numbers were found in the wild types (Yan et al. 2003).

Hematopoiesis is known to be regulated by a variety of chemokines and growth factors (Broxmeyer 2008). One of them, SDF1/CXCL12, is a substrate of CD26 (Campbell and Broxmeyer 2008). The CD26 deficiency increases the homing and growth of stem cells after transplantation in the bone marrow and thus leads to an improved maturation of lymphocytes (Christopherson et al. 2004). This could explain the higher numbers of $\mathrm{CD}^{+}{ }^{+} \mathrm{T}$ lymphocytes in the $\mathrm{CD} 26^{-}$animals on dpp7. Since only lung homogenates were used in the present work for the FACS analyses, a shift within the blood and lung compartments is also conceivable. It is known that CD26 is involved in the activation and transendothelial migration of $\mathrm{T}$ lymphocytes through its interaction with the mannose 6-phosphate/insulin-like growth factor II (Wagner et al. 2016). Different adhesion and migration of the T-lymphocytes on the vessel walls could therefore be explained by substrain-specific differences.

Interestingly, we found substrain-specific differences in the portions of activated $\mathrm{T}$ cells with regulatory functions characterized by $\mathrm{CD} 4{ }^{+} \mathrm{CD} 25^{+} \mathrm{T}$ cells during postnatal development independent of the inflammation. The population of regulatory cells comprises the $\mathrm{CD} 4{ }^{+} \mathrm{CD} 25^{+}$ regulatory $\mathrm{T}$ cells (Tregs) (Demengeot et al. 2006). Their function is governed by forkhead/winged helix transcription factor foxp3 (Hori et al. 2003). We did not determine this transcription factor, so that some of the $\mathrm{CD} 4{ }^{+} \mathrm{CD} 25^{+} \mathrm{T}$ cells are activated $\mathrm{CD} 4^{+} \mathrm{T}$ cells expressing the IL2 receptor. However, previous studies showed that nearly all activated $\mathrm{CD} 4{ }^{+} \mathrm{CD} 25^{+} \mathrm{T}$ cells in the lung also express the Foxp3 transcription factor (Schmiedl et al. 2010). The significantly higher values of $\mathrm{CD} 4{ }^{+} \mathrm{CD} 25^{+}$in the $\mathrm{CD} 26^{-}$group in controls as well as after LPS application compared to wild types are in accordance with results using DPP4 inhibitors leading to an upregulation of regulatory $\mathrm{T}$ cells (Tian et al. 2010). Furthermore, earlier results exhibited a significantly increased influx of $\mathrm{CD} 4{ }^{+} \mathrm{CD} 25^{+} \mathrm{FoxP} 3^{+}$into the lungs of $\mathrm{CD} 26^{-}$rats and increased IL-10-secretion/production by draining lymph node cells in culture, however, after OVA challenge (Schmiedl et al. 2010). Studies on knock-out mice showed similar results (Zhao 2019): CD26 knockout mice exhibited a delayed skin graft rejection combined with significantly reduced secretion of cytokines such as INFy, IL2, and IL4 but increased levels of IL 10 after skin transplantation. Additionally, a higher percentage of Tregs was detected in the peripheral blood lymphocytes (Zhao et al. 2019).

\section{LPS-induced modest parenchymal inflammation in lungs of both strains}

Exposure to LPS results in an increase of activated innate immune cells, such as neutrophils and macrophages to clear the infectious agent. However, after chronic LPS exposure, only a modest tissue inflammation was visible on dpp 7 and dpp10 characterized by low numbers per area of CD11b-positive inflammatory cells in lung parenchyma, which were admittedly higher on dpp 10 than on dpp 7 . However, macrophages barely increased and granulocytes increased modestly but significantly. This is in agreement 
with previous findings using an acute postnatal LPS inflammation model (Wagener et al. 2020) as well as with results of others (Ueda et al. 2006; Franco et al. 2002; Shrestha et al. 2019). When challenged with LPS, juvenile and adult mice show a more robust lung proinflammatory response than neonatal mice. Our data are consistent with this concept. A more pronounced LPS-induced activation of nuclear factor-light-chain enhancer in the lungs of adult compared to neonatal mice was shown (Alvira et al. 2007). Because this factor enhances B lymphocyte activation and is associated with increased lung inflammation, the airway inflammatory response was significantly greater in juvenile and adult mice than in neonatal mice (Alvira et al. 2007). Furthermore, the chemokine profile differed between juvenile and neonatal mice when challenged with LPS (Shrestha et al. 2019). In addition to this functional immaturity of the fetal immune system, the time period between LPS exposure and organ harvesting could also be important. In the adult animals, organs were obtained $9 \mathrm{~h}$ after LPS instillation (Zientara et al. 2019) in accordance with an established model by B. Singh, in which the inflammation peak occurs $9 \mathrm{~h}$ after LPS administration (Janardhan et al. 2004). Other groups reported a significant influx of inflammatory cells $6 \mathrm{~h}$ after LPS exposure and an inflammatory peak after about $24 \mathrm{~h}$ (Rinaldo et al. 1985). The extent to which these data can also be applied to newborns and young animals has not yet been clarified. In our studies, organs were harvested in the highdose LPS group $48 \mathrm{~h}$ after the LPS exposure in the acute inflammatory model (Wagener et al. 2020) or during (dpp 7) and at the end (dpp10) of LPS exposure in the presented chronical LPS model. And indeed, the inflammatory reaction was at dpp 7 and 10 during chronical LPS application somewhat higher than 2 days after the end of LPS exposure (Wagener et al. 2020). So, the time of intensity of inflammation may depend on the time interval between application and investigation not only in adults but also in newborn and pups, and repeated LPS application did not result in a tolerance combined with a weakened inflammation as described by others (Collins et al. 2013; Kramer et al. 2009).

\section{LPS modulates the composition of leucocyte subpopulations}

Within the first 10 days, the values of $\mathrm{CD}^{+} \mathrm{T}$ cells increased significantly in both groups. CD26 is expressed in different immune cells such as $\mathrm{CD} 4^{+} \mathrm{T}$ cells, $\mathrm{CD} 8^{+} \mathrm{T}$ cells, $\mathrm{B}$ cells, and macrophages and can additionally regulate these cells combined with the capacity to modulate a lot of cytokines and chemokines (Shao et al. 2020). Therefore, we suggested that the wild types apparently react with a stronger T-cell response to the LPS stimulus than the $\mathrm{CD} 26^{-}$animals and that there is a more or less pronounced upregulation of $\mathrm{CD} 26^{+} \mathrm{T}$ cells as seen in an asthma model of adult rats (Lun et al. 2007; Schade et al. 2008; Kruschinski et al. 2005). The missing remarkable response may be a result of the immaturity of the immune system in the neonatal mice. It is known that regulatory $\mathrm{T}$ cells diminish inflammatory responses by suppressing cytokine production by $\mathrm{CD} 4^{+}$and $\mathrm{CD} 8^{+} \mathrm{T}$ cells (Sakaguchi et al. 2010; Miyara and Sakaguchi 2007). Therefore, an increase of Tregs in LPS-induced animals should be expected as described for adult patients (Venet et al. 2009; Zanin-Zhorov et al. 2006; Hotchkiss et al. 2013). However, in our LPS model, the portion of $\mathrm{CD} 4{ }^{+} \mathrm{CD} 25^{+}$ $\mathrm{T}$ cells decreased in both subtypes significantly independent of the developmental stage. In a chronic LPS exposure model, treating newborn mice intraperitoneally with LPS on dpp 3-5, a decrease of Tregs was also found (Shrestha et al. 2019). These findings are further supported by detecting increased airway Tregs in juvenile but not in neonatal mice after intrapharyngeal administration of LPS (McGrathMorrow et al. 2015) and a decrease of percentage and absolute number of Tregs in fetal spleen and peripheral blood intraamniotic LPS application in a rhesus macaque model of chorioamnionitis (Rueda et al. 2016). Independent of LPS administration, Tregs decreased in the first postnatal weeks. Thus, the LPS-dependent alterations in the compositions of the immune cells are moderate and partly different to adults and may coincide with the weak inflammation seen in lung parenchyma, supporting the assumption of the functional immaturity of the perinatal immune system (Prince et al. 2004; Kramer et al. 2009; McGrath-Morrow et al. 2015).

\section{Influence of LPS on the lung development}

A retardation of alveolarization occurred in both substrains. The total septal surface in $\mathrm{CD}_{2} 6^{-}$pups remained reduced compared to controls on dpp 14. However, also in controls of $\mathrm{CD}^{-} 6^{-}$animals, values characterizing alveolarization such as the total septal surface as well as the total septal volume were partly significantly lower and the total parenchymal airspace significantly higher. No alterations were visible in the MLI as a measure of the mean free distances in airspaces and the arithmetic mean septal thickness. Therefore, the degree of maturation of the existing alveoli is comparable in both genotypes. However, fewer new alveoli were formed. An explanation may be that CD26 is involved in tumor necrosis factor $\beta$ (TGF- $\beta$ ) activation (Preller et al. 2007; Bauvois 2004), which is regarded as one precondition for alveolarization (Alejandre-Alcazar et al. 2008) and its interaction with fibronectin may be responsible for regular formation of septa and for timely alveolarization as discussed earlier (Wagener et al. 2020).

Thus, not only daily application of low doses of LPS for 7 days during alveolarization as carried out in this study, but also application of higher doses of LPS 1 day before and 
1 day after onset of alveolarization (Wagener et al. 2020) resulted in a retardation of lung development.

Newborn rats are born with morphologically immature lungs, which are comparable with those of immature infants born at 22 to 26 weeks of gestation (Burri 2006). The most critical factors for immature infants to develop a BPD may be oxidative stress caused by high oxygen concentrations and baro/volutrauma with mechanical ventilation (Shima et al. 2013), but also prenatal and postnatal inflammation (Choi et al. 2016; Speer 2006). There are numerous rodent models of BPD using hyperoxia as inducers (D'Angio and Ryan 2014; Berger and Bhandari 2014; O'Reilly and Thebaud 2014; Schmiedl et al. 2017). Another possibility is to induce BPD-like alterations by short-term administration of LPS prenatally or postnatally as shown by some authors (Schmiedl et al. 2011; Wagener et al. 2020; Ueda et al. 2006; Hou et al. 2015; Choi et al. 2016). The aim of a daily administration of low doses of LPS over a period of 7 days (from the 3rd to 9th postnatal day) undertaken in this study was to set a chronic inflammatory stimulus. Studies on continuous postnatal LPS exposure are desirable, because there was evidence that especially postnatal infection or sepsis increased the prevalence of BPD ( Jensen and Schmidt 2014; Balany and Bhandari 2015; Choi et al. 2016).

Our chronic LPS model led to mild inflammation as described for sheep lungs (Kramer et al. 2009). Other studies indicate that lungs are able to develop some tolerance to endotoxins after repeated treatment (Kallapur et al. 2007; Kramer 2011; Gisslen et al. 2014). If these results were also applied to the early rat lung, the very first LPS exposure on day 3 would be the crucial inflammatory stimulus, which would have subsided on days 7 and 10. Choi and colleagues (Choi et al. 2009) demonstrated that LPS administered during the saccular period interrupts alveolarization and pulmonary vascularization at dpp 7 and dpp 14 .

\section{Conclusions}

Chronical application of LPS leads to a weak inflammatory response, and to a retardation of pulmonary development also seen in animal models using higher dosed LPS.

Looking at the immune status, CD26-dependent differences are already seen without LPS, confirming partly the mediator role of $\mathrm{CD} 26$ during T cell activation. Chronical LPS exposure results in moderate CD26-dependent alterations in the immune cell contents, leading in $\mathrm{CD} 26^{-}$pups to a retarded increase of $\mathrm{CD} 4{ }^{+} \mathrm{T}$ cells combined with a significant increase of monocytes/macrophages.

Acknowledgements The authors thank Susanne Faßbender, Susanne Kuhlmann, and Andrea Herden for their excellent technical assistance as well as Prof. Dr. med. Reinhard Pabst for critical reading and valuable comments and Dr. Stephanie Groos for her advice and support in creating and arranging the pictures. We also thank Sheila Fryk for correction of the English text.

Funding Open Access funding enabled and organized by Projekt DEAL. This work was supported by grants from the Deutsche Forschungsgemeinschaft (SFB 587; Project B11). Parts of the results are found in the doctoral theses of Inga Schünke and Meike Jungen.

\section{Declarations}

Ethics approval All applicable international, national, and/or institutional guidelines for the care and use of animals were followed and approved by the Landesamt für Verbraucherschutz und Lebensmittelsicherheit (06/1078, LAVES; Oldenburg, Germany).

Conflict of interest The authors declare no competing interests.

Open Access This article is licensed under a Creative Commons Attribution 4.0 International License, which permits use, sharing, adaptation, distribution and reproduction in any medium or format, as long as you give appropriate credit to the original author(s) and the source, provide a link to the Creative Commons licence, and indicate if changes were made. The images or other third party material in this article are included in the article's Creative Commons licence, unless indicated otherwise in a credit line to the material. If material is not included in the article's Creative Commons licence and your intended use is not permitted by statutory regulation or exceeds the permitted use, you will need to obtain permission directly from the copyright holder. To view a copy of this licence, visit http://creativecommons.org/licenses/by/4.0/.

\section{References}

Alejandre-Alcazar MA, Michiels-Corsten M, Vicencio AG, Reiss I, Ryu J, de Krijger RR, Haddad GG, Tibboel D, Seeger W, Eickelberg O, Morty RE (2008) TGF-beta signaling is dynamically regulated during the alveolarization of rodent and human lungs. Dev Dyn 237:259-269

Alvira CM, Abate A, Yang G, Dennery PA, Rabinovitch M (2007) Nuclear factor-kappaB activation in neonatal mouse lung protects against lipopolysaccharide-induced inflammation. Am J Respir Crit Care Med 175:805-815

Anderson KV (2000) Toll signaling pathways in the innate immune response. Curr Opin Immunol 12:13-19

Baker CD, Alvira CM (2014) Disrupted lung development and bronchopulmonary dysplasia: opportunities for lung repair and regeneration. Curr Opin Pediatr 26:306-314

Balany J, Bhandari V (2015) Understanding the impact of infection, inflammation, and their persistence in the pathogenesis of bronchopulmonary dysplasia. Front Med (lausanne) 2:90

Ballard AR, Mallett LH, Pruszynski JE, Cantey JB (2016) Chorioamnionitis and subsequent bronchopulmonary dysplasia in very-lowbirth weight infants: a 25-year cohort. J Perinatol 36:1045-1048

Bauvois B (2004) Transmembrane proteases in cell growth and invasion: new contributors to angiogenesis? Oncogene 23:317-329

Berger J, Bhandari V (2014) Animal models of bronchopulmonary dysplasia. The term mouse models. Am J Physiol Lung Cell Mol Physiol 307:L936-L947

Broxmeyer HE (2008) Chemokines in hematopoiesis. Curr Opin Hematol 15:49-58 
Broxmeyer HE, Capitano M, Campbell TB, Hangoc G, Cooper S (2016) Modulation of hematopoietic chemokine effects in vitro and in vivo by DPP-4/CD26. Stem Cells Dev 25:575-585

Buhling F, Junker U, Reinhold D, Neubert K, Jager L, Ansorge S (1995) Functional role of CD26 on human B lymphocytes. Immunol Lett 45:47-51

Burri PH (2006) Structural aspects of postnatal lung development alveolar formation and growth. Biol Neonate 89:313-322

Campbell TB, Broxmeyer HE (2008) CD26 inhibition and hematopoiesis: a novel approach to enhance transplantation. Front Biosci 13:1795-1805

Cao L, Wang J, Tseu I, Luo D, Post M (2009) Maternal exposure to endotoxin delays alveolarization during postnatal rat lung development. Am J Physiol Lung Cell Mol Physiol 296:L726-L737

Choi CW, Kim BI, Hong JS, Kim EK, Kim HS, Choi JH (2009) Bronchopulmonary dysplasia in a rat model induced by intra-amniotic inflammation and postnatal hyperoxia: morphometric aspects. Pediatr Res 65:323-327

Choi CW, Lee J, Oh JY, Lee SH, Lee HJ, Kim BI (2016) Protective effect of chorioamnionitis on the development of bronchopulmonary dysplasia triggered by postnatal systemic inflammation in neonatal rats. Pediatr Res 79:287-294

Christopherson KW, Hangoc G, Mantel CR, Broxmeyer HE (2004) Modulation of hematopoietic stem cell homing and engraftment by CD26. Science 305:1000-1003

Coalson JJ (2006) Pathology of bronchopulmonary dysplasia. Semin Perinatol 30:179-184

Collins JJ, Kallapur SG, Knox CL, Kemp MW, Kuypers E, Zimmermann LJ, Newnham JP, Jobe AH, Kramer BW (2013) Repeated intrauterine exposures to inflammatory stimuli attenuated transforming growth factor-beta signaling in the ovine fetal lung. Neonatology 104:49-55

Cooney TP, Thurlbeck WM (1982a) The radial alveolar count method of Emery and Mithal: a reappraisal 1-postnatal lung growth. Thorax 37:572-579

Cooney TP, Thurlbeck WM (1982b) The radial alveolar count method of Emery and Mithal: a reappraisal 2-intrauterine and early postnatal lung growth. Thorax 37:580-583

D'Angio CT, Ryan RM (2014) Animal models of bronchopulmonary dysplasia. The preterm and term rabbit models. Am J Physiol Lung Cell Mol Physiol 307:L959-L969

Dasgupta C, Sakurai R, Wang Y, Guo P, Ambalavanan N, Torday JS, Rehan VK (2009) Hyperoxia-induced neonatal rat lung injury involves activation of TGF- $\{$ beta $\}$ and Wnt signaling and is protected by rosiglitazone. Am J Physiol Lung Cell Mol Physiol 296:L1031-L1041

Dauger S, Ferkdadji L, Saumon G, Vardon G, Peuchmaur M, Gaultier C, Gallego J (2003) Neonatal exposure to $65 \%$ oxygen durably impairs lung architecture and breathing pattern in adult mice. Chest 123:530-538

De Paepe ME, Friedman RM, Gundogan F, Pinar H (2005) Postmortem lung weight/body weight standards for term and preterm infants. Pediatr Pulmonol 40:445-448

De Paepe ME, Shapiro S, Hansen K, Gundogan F (2014) Postmortem lung volume/body weight standards for term and preterm infants. Pediatr Pulmonol 49:60-66

Demengeot J, Zelenay S, Moraes-Fontes MF, Caramalho I, Coutinho A (2006) Regulatory T cells in microbial infection. Springer Semin Immunopathol 28:41-50

Eder W, von Mutius E (2004) Hygiene hypothesis and endotoxin: what is the evidence? Curr Opin Allergy Clin Immunol 4:113-117

Franco ML, Waszak P, Banalec G, Levame M, Lafuma C, Harf A, Delacourt C (2002) LPS-induced lung injury in neonatal rats: changes in gelatinase activities and consequences on lung growth. Am J Physiol Lung Cell Mol Physiol 282:L491-L500
Gerhold K, Bluemchen K, Franke A, Stock P, Hamelmann E (2003) Exposure to endotoxin and allergen in early life and its effect on allergen sensitization in mice. J Allergy Clin Immunol 112:389-396

Gisslen T, Hillman NH, Musk GC, Kemp MW, Kramer BW, Senthamaraikannan P, Newnham JP, Jobe AH, Kallapur SG (2014) Repeated exposure to intra-amniotic LPS partially protects against adverse effects of intravenous LPS in preterm lambs. Innate Immun 20:214-224

Herring MJ, Putney LF, Wyatt G, Finkbeiner WE, Hyde DM (2014) Growth of alveoli during postnatal development in humans based on stereological estimation. Am J Physiol Lung Cell Mol Physiol 307:L338-L344

Hori S, Nomura T, Sakaguchi S (2003) Control of regulatory T cell development by the transcription factor Foxp3. Science 299:1057-1061

Hotchkiss RS, Monneret G, Payen D (2013) Sepsis-induced immunosuppression: from cellular dysfunctions to immunotherapy. Nat Rev Immunol 13:862-874

Hou Y, Liu M, Husted C, Chen C, Thiagarajan K, Johns JL, Rao SP, Alvira CM (2015) Activation of the nuclear factor-kappaB pathway during postnatal lung inflammation preserves alveolarization by suppressing macrophage inflammatory protein- 2 . Am J Physiol Lung Cell Mol Physiol 309:L593-L604

Hsia CC, Hyde DM, Ochs M, Weibel ER (2010) How to measure lung structure-what for? On the "Standards for the quantitative assessment of lung structure.” Respir Physiol Neurobiol 171:72-74

Hupa KL, Schmiedl A, Pabst R, von Hörsten S, Stephan M (2014) Maternal deprivation decelerates postnatal morphological lung development of f344 rats. Anat Rec (hoboken ) 297:317-326

Husain AN, Siddiqui NH, Stocker JT (1998) Pathology of arrested acinar development in postsurfactant bronchopulmonary dysplasia. Hum Pathol 29:710-717

Janardhan KS, Appleyard GD, Singh B (2004) Expression of integrin subunits alpha $v$ and beta 3 in acute lung inflammation. Histochem Cell Biol 121:383-390

Jensen EA, Schmidt B (2014) Epidemiology of bronchopulmonary dysplasia. Birth Defects Res A Clin Mol Teratol 100:145-157

Jobe AH (2015) Animal models, learning lessons to prevent and treat neonatal chronic lung disease. Front Med (lausanne) 2:49

Kallapur SG, Jobe AH, Ball MK, Nitsos I, Moss TJ, Hillman NH, Newnham JP, Kramer BW (2007) Pulmonary and systemic endotoxin tolerance in preterm fetal sheep exposed to chorioamnionitis. J Immunol 179:8491-8499

Karl T, Chwalisz WT, Wedekind D, Hedrich HJ, Hoffmann T, Jacobs R, Pabst R, von Hörsten S (2003) Localization, transmission, spontaneous mutations, and variation of function of the Dpp4 (Dipeptidyl-peptidase IV; CD26) gene in rats. Regul Pept 115:81-90

Kawasaki T, Chen W, Htwe YM, Tatsumi K, Dudek SM (2018) DPP4 inhibition by sitagliptin attenuates LPS-induced lung injury in mice. Am J Physiol Lung Cell Mol Physiol

Klemann C, Schade J, Pabst R, Leitner S, Stiller J, von Hörsten S, Stephan M (2009) CD26/dipeptidyl peptidase 4-deficiency alters thymic emigration patterns and leukcocyte subsets in F344-rats age-dependently. Clin Exp Immunol 155:357-365

Klemann C, Wagner L, Stephan M, von Hörsten S (2016) Cut to the chase: a review of CD26/dipeptidyl peptidase-4's (DPP4) entanglement in the immune system. Clin Exp Immunol 185:1-21

Knudsen L, Weibel ER, Gundersen HJ, Weinstein FV (1985) Ochs M (2010) Assessment of air space size characteristics by intercept (chord) measurement: an accurate and efficient stereological approach. J Appl Physiol 108:412-421

Kramer BW (2011) Chorioamnionitis - new ideas from experimental models. Neonatology 99:320-325 
Kramer BW, Kallapur S, Newnham J, Jobe AH (2009) Prenatal inflammation and lung development. Semin Fetal Neonatal Med 14:2-7

Kruschinski C, Skripuletz T, Bedoui S, Raber K, Straub RH, Hoffmann T, Grote K, Jacobs R, Stephan M, Pabst R, von Hörsten S (2008) Postnatal life events affect the severity of asthmatic airway inflammation in the adult rat. J Immunol 180:3919-3925

Kruschinski C, Skripuletz T, Bedoui S, Tschernig T, Pabst R, Nassenstein C, Braun A, von Hörsten S (2005) CD26 (dipeptidyl-peptidase IV)dependent recruitment of $\mathrm{T}$ cells in a rat asthma model. Clin Exp Immunol 139:17-24

Liu F, Li W, Pauluhn J, Trubel H, Wang C (2013) Lipopolysaccharideinduced acute lung injury in rats: comparative assessment of intratracheal instillation and aerosol inhalation. Toxicology 304:158-166

Lun SW, Wong CK, Ko FW, Hui DS, Lam CW (2007) Increased expression of plasma and CD4+ T lymphocyte costimulatory molecule CD26 in adult patients with allergic asthma. J Clin Immunol 27:430-437

Manzano RM, Mascaretti RS, Carrer V, Haddad LB, Fernandes AR, Reyes AM, Rebello CM (2014) A hyperoxic lung injury model in premature rabbits: the influence of different gestational ages and oxygen concentrations. PLoS One 9:e95844

Martin TR, Frevert CW (2005) Innate immunity in the lungs. Proc Am Thorac Soc 2:403-411

McGrath-Morrow SA, Lee S, Gibbs K, Lopez A, Collaco JM, Neptune E, Soloski MJ, Scott A, D’Alessio F (2015) Immune response to intrapharyngeal LPS in neonatal and juvenile mice. Am J Respir Cell Mol Biol 52:323-331

Mentlein R (1999) Dipeptidyl-peptidase IV (CD26)-role in the inactivation of regulatory peptides. Regul Pept 85:9-24

Miyara M, Sakaguchi S (2007) Natural regulatory T cells: mechanisms of suppression. Trends Mol Med 13:108-116

Nardiello C, Mizikova I, Silva DM, Ruiz-Camp J, Mayer K, Vadasz I, Herold S, Seeger W, Morty RE (2017) Standardisation of oxygen exposure in the development of mouse models for bronchopulmonary dysplasia. Dis Model Mech 10:185-196

O'Reilly M, Thebaud B (2014) Animal models of bronchopulmonary dysplasia. The term rat models. Am J Physiol Lung Cell Mol Physiol 307:L948-L958

Ochs M (2014) Estimating structural alterations in animal models of lung emphysema. Is there a gold standard? Ann Anat 196:26-33

Ohnuma K, Dang NH, Morimoto C (2008) Revisiting an old acquaintance: CD26 and its molecular mechanisms in T cell function. Trends Immunol 29:295-301

Pabst R, Luhrmann A, Steinmetz I, Tschernig T (2003) A single intratracheal dose of the growth factor Fms-like tyrosine kinase receptor-3 ligand induces a rapid differential increase of dendritic cells and lymphocyte subsets in lung tissue and bronchoalveolar lavage, resulting in an increased local antibody production. $\mathbf{J}$ Immunol 171:325-330

Pozarska A, Rodriguez-Castillo JA, Surate Solaligue DE, Ntokou A, Rath P, Mizikova I, Madurga A, Mayer K, Vadasz I, Herold S, Ahlbrecht K, Seeger W, Morty RE (2017) Stereological monitoring of mouse lung alveolarization from the early postnatal period to adulthood. Am J Physiol Lung Cell Mol Physiol 312:L882-L895

Preller V, Gerber A, Wrenger S, Togni M, Marguet D, Tadje J, Lendeckel U, Rocken C, Faust J, Neubert K, Schraven B, Martin R, Ansorge S, Brocke S, Reinhold D (2007) TGF-beta1-mediated control of central nervous system inflammation and autoimmunity through the inhibitory receptor CD26. J Immunol 178:4632-4640

Prince LS, Okoh VO, Moninger TO, Matalon S (2004) Lipopolysaccharide increases alveolar type II cell number in fetal mouse lungs through Toll-like receptor 4 and NF-kappaB. Am J Physiol Lung Cell Mol Physiol 287:L999-1006
Proost P, Menten P, Struyf S, Schutyser E, De Meester I, Van Damme J (2000) Cleavage by CD26/dipeptidyl peptidase IV converts the chemokine LD78beta into a most efficient monocyte attractant and CCR1 agonist. Blood 96:1674-1680

Rehbinder C, Baneux P, Forbes D, van Herck H, Nicklas W, Rugaya Z, Winkler G (1996) FELASA recommendations for the health monitoring of mouse, rat, hamster, gerbil, guinea pig and rabbit experimental units. Report of the Federation of European Laboratory Animal Science Associations (FELASA) Working Group on Animal Health accepted by the FELASA Board of Management, November 1995. Lab Anim 30:193-208

Reinhold D, Goihl A, Wrenger S, Reinhold A, Kuhlmann UC, Faust J, Neubert K, Thielitz A, Brocke S, Tager M, Ansorge S, Bank U (2009) Role of dipeptidyl peptidase IV (DP IV)-like enzymes in T lymphocyte activation: investigations in DP IV/CD26-knockout mice. Clin Chem Lab Med 47:268-274

Reinhold D, Kahne T, Tager M, Lendeckel U, Buhling F, Bank U, Wrenger S, Faust J, Neubert K, Ansorge S (1997) The effect of anti-CD26 antibodies on DNA synthesis and cytokine production (IL-2, IL-10 and IFN-gamma) depends on enzymatic activity of DP IV/CD26. Adv Exp Med Biol 421:149-155

Rinaldo JE, Henson JE, Dauber JH, Henson PM (1985) Role of alveolar macrophages in endotoxin-induced neutrophilic alveolitis in rats. Tissue Cell 17:461-472

Rossol M, Heine H, Meusch U, Quandt D, Klein C, Sweet MJ, Hauschildt S (2011) LPS-induced cytokine production in human monocytes and macrophages. Crit Rev Immunol 31:379-446

Rueda CM, Presicce P, Jackson CM, Miller LA, Kallapur SG, Jobe AH, Chougnet CA (2016) Lipopolysaccharide-induced chorioamnionitis promotes IL-1-dependent inflammatory FOXP3+ CD4+ T Cells in the Fetal Rhesus Macaque. J Immunol 196:3706-3715

Sakaguchi S, Miyara M, Costantino CM, Hafler DA (2010) FOXP3+ regulatory $\mathrm{T}$ cells in the human immune system. Nat Rev Immunol 10:490-500

Sapolsky RM, Meaney MJ (1986) Maturation of the adrenocortical stress response: neuroendocrine control mechanisms and the stress hyporesponsive period. Brain Res 396:64-76

Schade J, Stephan M, Schmiedl A, Wagner L, Niestroj AJ, Demuth HU, Frerker N, Klemann C, Raber KA, Pabst R, von Hörsten S (2008) Regulation of expression and function of dipeptidyl peptidase 4 (DP4), DP8/9, and DP10 in allergic responses of the lung in rats. J Histochem Cytochem 56:147-155

Scherle W (1970) A simple method for volumetry of organs in quantitative stereology. Mikroskopie 26:57-60

Schittny JC (2017) Development of the lung. Cell Tissue Res 367:427-444

Schmiedl A, Behrens J, Zscheppang K, Purevdorj E, von Meyersbach D, Liese A, Dammann CE (2011) Lipopolysaccharide-induced injury is more pronounced in fetal transgenic ErbB4-deleted lungs. Am J Physiol Lung Cell Mol Physiol 301:L490-L499

Schmiedl A, Krainski J, Schwichtenhovel F, Schade J, Klemann C, Raber KA, Zscheppang K, Beekmann T, Acevedo C, Glaab T, Wedekind D, Pabst R, von Hörsten S, Stephan M (2010) Reduced airway inflammation in CD26/DPP4-deficient F344 rats is associated with altered recruitment patterns of regulatory $\mathrm{T}$ cells and expression of pulmonary surfactant proteins. Clin Exp Allergy 40:1794-1808

Schmiedl A, Roolfs T, Tutdibi E, Gortner L, Monz D (2017) Influence of prenatal hypoxia and postnatal hyperoxia on morphologic lung maturation in mice. PLOS ONE 12:e0175804

Shao S, Xu Q, Yu X, Pan R, Chen Y (2020) Dipeptidyl peptidase 4 inhibitors and their potential immune modulatory functions. Pharmacol Ther 209:107503

Shima Y, Kumasaka S, Migita M (2013) Perinatal risk factors for adverse long-term pulmonary outcome in premature infants: 
comparison of different definitions of bronchopulmonary dysplasia/chronic lung disease. Pediatr Int 55:578-581

Shrestha AK, Bettini ML, Menon RT, Gopal VYN, Huang S, Edwards DP, Pammi M, Barrios R, Shivanna B (2019) Consequences of early postnatal lipopolysaccharide exposure on developing lungs in mice. Am J Physiol Lung Cell Mol Physiol 316:L229-L244

Skripuletz T, Schmiedl A, Schade J, Bedoui S, Glaab T, Pabst R, von Hörsten S, Stephan M (2007) Dose-dependent recruitment of CD25+ and CD26+ T cells in a novel F344 rat model of asthma. Am J Physiol Lung Cell Mol Physiol 292:L1564-L1571

Speer CP (2006) Pulmonary inflammation and bronchopulmonary dysplasia. J Perinatol 26(Suppl 1):S57-S62

Takeda K, Kaisho T, Akira S (2003) Toll-like receptors. Annu Rev Immunol 21:335-376

Tian L, Gao J, Hao J, Zhang Y, Yi H, O’Brien TD, Sorenson R, Luo J, Guo Z (2010) Reversal of new-onset diabetes through modulating inflammation and stimulating beta-cell replication in nonobese diabetic mice by a dipeptidyl peptidase IV inhibitor. Endocrinology 151:3049-3060

Tiono J, Surate Solaligue DE, Mizikova I, Nardiello C, Vadasz I, Bottcher-Friebertshauser E, Ehrhardt H, Herold S, Seeger W, Morty RE (2019) Mouse genetic background impacts susceptibility to hyperoxia-driven perturbations to lung maturation. Pediatr Pulmonol 54:1060-1077

Tschanz SA, Salm LA, Roth-Kleiner M, Barre SF, Burri PH, Schittny JC (2014) Rat lungs show a biphasic formation of new alveoli during postnatal development. J Appl Physiol 117:89-95

Ueda K, Cho K, Matsuda T, Okajima S, Uchida M, Kobayashi Y, Minakami H, Kobayashi K (2006) A rat model for arrest of alveolarization induced by antenatal endotoxin administration. Pediatr Res 59:396-400

Van Damme J, Struyf S, Wuyts A, Van Coillie E, Menten P, Schols D, Sozzani S, De Meester I, Proost P (1999) The role of CD26/DPP IV in chemokine processing. Chem Immunol 72:42-56

Venet F, Chung CS, Kherouf H, Geeraert A, Malcus C, Poitevin F, Bohe J, Lepape A, Ayala A, Monneret G (2009) Increased circulating regulatory T cells $(\mathrm{CD} 4(+) \mathrm{CD} 25(+) \mathrm{CD} 127(-))$ contribute to lymphocyte anergy in septic shock patients. Intensive Care Med 35:678-686

Wagener I, Jungen M, von Hörsten S, Stephan M, Schmiedl A (2020) Postnatal morphological lung development of wild type and CD26/DPP4 deficient rat pups in dependency of LPS exposure. Ann Anat 229:151423

Wagner L, Klemann C, Stephan M, von Hörsten S (2016) Unravelling the immunological roles of dipeptidyl peptidase 4 (DPP4) activity and/or structure homologue (DASH) proteins. Clin Exp Immunol 184:265-283

Wang X, Hellgren G, Lofqvist C, Li W, Hellstrom A, Hagberg H, Mallard C (2009) White matter damage after chronic subclinical inflammation in newborn mice. J Child Neurol 24:1171-1178

Yan S, Marguet D, Dobers J, Reutter W, Fan H (2003) Deficiency of CD26 results in a change of cytokine and immunoglobulin secretion after stimulation by pokeweed mitogen. Eur J Immunol 33:1519-1527

Zanin-Zhorov A, Cahalon L, Tal G, Margalit R, Lider O, Cohen IR (2006) Heat shock protein 60 enhances CD4+ CD25+ regulatory $\mathrm{T}$ cell function via innate TLR2 signaling. J Clin Invest 116:2022-2032

Zhao X, Zhang K, Daniel P, Wisbrun N, Fuchs H, Fan H (2019) Delayed allogeneic skin graft rejection in CD26-deficient mice. Cell Mol Immunol 16:557-567

Zhao Y (2019) CD26 in autoimmune diseases: the other side of "moonlight protein". Int Immunopharmacol 75:105757

Zientara A, Stephan M, von Hörsten S, Schmiedl A (2019) Differential severity of LPS-induced lung injury in CD26/DPP4 positive and deficient F344 rats. Histol Histopatho 34:1151-1171

Zoetis T, Hurtt ME (2003) Species comparison of lung development. Birth Defects Res B Dev Reprod Toxicol 68:121-124

Publisher's Note Springer Nature remains neutral with regard to jurisdictional claims in published maps and institutional affiliations. 